\title{
Control-Oriented Modeling Analysis and Optimization of Planar Solid Oxide Fuel Cell System
}

\author{
Huan Cheng ${ }^{\mathbf{a}}$, Suwen Jing ${ }^{\mathbf{a}}$, Yuanwu Xu ${ }^{\mathbf{a}}$, Zhonghua Deng ${ }^{\mathbf{a}}$, \\ Jian $\mathrm{Li}^{\mathbf{b}}, \mathrm{Xi} \mathrm{Li}^{\mathbf{a}, *}$
}

a) School of automation, Key Laboratory of Education Ministry for Image

Processing and Intelligent Control, Huazhong University of Science \& Technology,

Wuhan, 430074, China

b) School of Materials Science and Engineering, State Key Laboratory of

Material Processing and Die and Mould Technology, Huazhong University of Science \& Technology, Wuhan 430074, China

\begin{abstract}
Because of multi-timescale characteristics and gas transmission delays, the thermal electrical cooperative control of solid oxide fuel cells is a complex and difficult issue. We have used modeling, analysis and optimization of a solid oxide fuel cell system control to guarantee a high efficiency and temperature safety during steady-state and power switch transients. An analysis-based optimization method that applies to discrete optimization problem with constraints is proposed to obtain optimal operating points with a maximum efficiency and to satisfy temperature constraints. Artificial neural-network models that were identified from a validated
\end{abstract}

*Corresponding author: Tel: +86 027-87558142 Fax: +86 027-87558142

E-mail address:1ixi_wh@126.com (Xi Li) 
two-dimensional differential model were used to analyze the temperature constraints and system efficiency. Compared with traversal optimization in literature, the proposed optimization method could save more than $90 \%$ of the workload and allow for a more reasonable choice of variable discrete precision. The optimization results were proven feasible by the proposed new system structure and stack inlet condition-based control strategy. The simulation results show that the key problems of the solid oxide fuel cell system control, which include temperature safety, fast load following, fuel starvation and efficiency promotion, could be solved by the proposed strategy.

Keywords: Analysis-based efficiency optimization; Artificial neural network; Optimal operating points; Planar solid oxide fuel cell; Thermal electrical cooperative control 


\section{Nomenclature}

\begin{tabular}{|c|c|}
\hline$A$ & Area $\left(m^{2}\right)$ \\
\hline$C$ & Specific heat capacity $\left(J \cdot m o l^{-1} \cdot K^{-1}\right)$ or Constant \\
\hline$d$ & Distance $(m)$ \\
\hline$F$ & Mole flow rate $\left(\mathrm{mol} \cdot \mathrm{s}^{-1}\right)$ \\
\hline & or Faraday's constant $\left(=96485 \mathrm{C} \cdot \mathrm{mol}^{-1}\right)$ \\
\hline$h$ & Enthalpy $\left(J \cdot m o l^{-1}\right)$ \\
\hline$I$ & Current $(A)$ \\
\hline$I^{(i j)}$ & Current of the $(i \quad j)$ th node $(A)$ \\
\hline$k$ & Heat transmission coefficient $\left(k W \cdot K^{-1} \cdot m^{-2}\right)$ \\
\hline$L$ & Length of cell $(m)$ \\
\hline$N$ & Mole number \\
\hline$P$ & Intensity of pressure ( $\mathrm{Pa}$ ) \\
\hline$R$ & Ideal gas constant $\left(=8.314 \mathrm{~J} \cdot \mathrm{mol}^{-1} \cdot \mathrm{K}^{-1}\right)$ \\
\hline$T$ & Temperature $(K)$ \\
\hline$V$ & Volume $\left(m^{3}\right)$ \\
\hline$V_{\text {cell }}$ & The voltage of single cells $(V)$ \\
\hline$W$ & Width of cell $(m)$ \\
\hline & Mole fraction \\
\hline
\end{tabular}

Greek letters

$\rho$

Density $\left(\mathrm{kg} \cdot \mathrm{m}^{-3}\right)$ 


\begin{tabular}{|c|c|}
\hline$\tau$ & Thickness $(m)$ \\
\hline$\eta$ & Voltage loss by polarization $(V)$ \\
\hline$\lambda$ & Weight \\
\hline \multicolumn{2}{|c|}{ Subscripts } \\
\hline in & Inlet \\
\hline act & Activation \\
\hline avg & Average \\
\hline con & Concentration \\
\hline grd & Temperature gradient \\
\hline$i c$ & Interconnector \\
\hline$\left(\begin{array}{ll}i & j\end{array}\right)$ & $\left(\begin{array}{ll}i & j\end{array}\right)$ th node \\
\hline load & Electronic load \\
\hline ohm & Ohmic \\
\hline pen & Positive electrode-Electrolyte-Negative electrode \\
\hline$r a$ & Reaction \\
\hline rc & Recirculation \\
\hline sol & Solid structure \\
\hline$s p$ & Supply \\
\hline tot & Total \\
\hline
\end{tabular}




\section{Introduction}

Solid oxide fuel cells (SOFCs) are considered to be a promising future power generation technology because of their high efficiency and low emissions. Their high operating temperature $\left(600-1000^{\circ} \mathrm{C}\right)$ allows $\mathrm{SOFCs}$ to have a more varied and tolerable fuel strategy. However, the SOFC high-temperature operation brings about numerous challenges for system control. Thermal management and efficiency optimization are two key problems to be solved before controller design.

The most difficult part of thermal management is to guarantee SOFC stack operating within certain temperature constraints. The stack should be operated within a distinct temperature range in which the upper limit is given by the material properties and the lower limit is given by the ionic conductivity of the electrolyte [1]. The stack temperature distribution should be kept uniform to avoid large temperature gradients, which are a primary cause of thermal stress [1-4]. Excessive thermal stress in the SOFC stack would lead to thermal failure $[1,4-6]$. Because stacks are the core of the SOFC system and are very sensitive to certain temperature constraints, research into the stack temperature distribution is very significant. Extensive modeling and analysis of the stack temperature distribution has been conducted in the literature [7-12]. Model validation was not provided in [7-9]. The model in [11,12] was validated by an I-V curve that was obtained experimentally. In [10], the model was validated by temperature data in the literature, but the published data could not describe the temperature distribution in the SOFC stack because these data include only the air temperature at the stack outlet and the maximum temperature of the stack 
solid structure. Model validations of the stack temperature distribution in literature are insufficient. Most thermal analyses concentrate on the influence of temperature distribution on thermal stress or the effects of different parameters on SOFC temperature distributions, such as flow configurations and material properties. However, to provide information for thermal management, what we want to determine is how to affect stack temperature distribution by adjusting stack inlet operating parameters. We built a two-dimensional (2D) differential model, which was validated using the electrical characteristics and temperature distribution. Artificial neural network (ANN) models were identified to aid in the temperature analysis.

Efficiency optimization that is based on temperature safety is another important and basic issue for SOFC system control. Because the SOFC system is too complex to abstract an analytical relationship between SOFC operating parameters and efficiency, the optimization was always done by discrete approximation [13-15]. Firstly, operating parameters were discretized in their value ranges and the discrete precision of different operating parameters was chosen by experience and insight. Every combination of the discrete values of the operating parameters represents an operating point. A simulation was done on all operating points to solve the corresponding temperature and efficiency outputs. Finally, the optimal operating point with the maximum efficiency and satisfying temperature constraints was determined from all the points. To approximate the continuous situation, the operating points must be sufficiently dense in their value ranges. However, too many operating points will increase the simulation time. In [15], a cubic convolution interpolation algorithm was 
used to replace part of the simulation. However, the traverse optimization process in [13-15] requires that all discrete operating points be considered. We proposed an analysis-based optimization method to optimize the system efficiency. The proposed optimization method is more efficient than traverse optimization because discrete precision variables were chosen based on their influencing weights on efficiency, and more than $90 \%$ of the operating points were eliminated from the candidate of the optimal operating points (OOPs) by analysis.

To implement the optimization conclusion and to achieve thermal electrical cooperative control, a novel system structure and a controller based on this system structure were proposed. The challenge of the SOFC system control is to consider temperature safety and load following simultaneously on the premise of avoiding fuel starvation. Much research has been done in this area and many achievements have been made [16-23]. However, most of these works focus either on temperature safety or load following and rarely consider both. Research in [3,24,25] shows that gas bypass addition to a SOFC system could yield more degrees of freedom on system control, whereas the work in $[3,25,26]$ indicates that fuel recovery could enhance the overall fuel use. Inspired by these published work, we included three gas bypasses and fuel recovery in this new proposed system structure to aid the SOFC system control. The effectiveness of this structure and a corresponding controller were proven by simulation.

The remainder of the paper is organized as follows. A 2D differential model was built and is validated for a cross-flow SOFC stack in section 2. The SOFC efficiency 
optimization problem is described in section 3. An analysis-based efficiency optimization of the SOFC system is given in section 4. In section 5, a new SOFC system structure and a control strategy are proposed according to the optimization result, followed by the conclusions in section 6 .

\section{Modeling and Validation of SOFC stack}

In this section, a 2D differential model is built by a finite-volume method and is validated experimentally.

\subsection{Modeling}

The working principle and basic structure of the cross-flow SOFC stack are shown in Fig. 1. Different from co-flow, the air and fuel enter the cross-flow stack in two vertical directions. Therefore, a 2D model is needed for the cross-flow stack.

Similar with what we did in [27], the finite-volume method is used again to build the model for a cross-flow stack. Along the air and fuel flow direction, the stack is equidistantly divided into $m \times n$ nodes as illustrated in Fig. 2. To reduce the computational complexity, $m$ and $n$ are taken as being equal to 5 in this paper.

The cross-flow stack model in this paper is based on physical conservation laws that are essentially the same, with the co-flow stack model built by us in [27]. The difference between the cross- and co-flow stack models is the method of heat transport in their stack solid structures. The solid structure in a co-flow stack transfer heat with two preceding and subsequent nodes and the solid structure in a cross-flow stack will transfer heat with the four nodes before, after, upwards and downwards of itself. The different heat transport types initiate different temperature distributions in 
co- and cross-flow stacks.

Differences in heat transfer can be changed in the modeling process. Therefore, the model equations are omitted here to save space and the model validation will be taken as the emphasis.

\subsection{Model validation}

A 5-cell stack experiment was conducted in a furnace at $750^{\circ} \mathrm{C}$. The experimental platform and cross-flow assembling form are shown in Fig. 3. The cell was anode-supported $(10 \mathrm{~cm} \times 10 \mathrm{~cm})$ with an $81 \mathrm{~cm}^{2}$ reaction active area. The cell was manufactured in-house with the manufacturing process described in detail in [12]. Essential cell information is given in Table 1.

The experimental conditions were: hydrogen and air flow rates of $8 \mathrm{~L} \mathrm{~min}^{-1}$, and hydrogen and air that were preheated in a furnace to $\sim 898 \mathrm{~K}$ and $\sim 873 \mathrm{~K}$ before being fed into the stack. The measured and calculated average single cell voltages for different currents are compared in Table 2. The average voltage error was $0.0058 \mathrm{~V}$ and its error ratio was $0.66 \%$. The agreement between the experimental and calculated voltages was good.

To measure the stack temperature distribution, five K-type thermocouples (with a 0.5-mm diameter) were placed in the middle cell of the stack. The thermocouple configuration is shown in Fig. 4 (a). A comparison of the measured and calculated temperature distributions is given in Figs 4 (b) and (c).

The stack current was maintained at 20 A for more than half an hour before the temperatures were recorded. The average temperature error was $3.6 \mathrm{~K}$ and its error 
ratio was $0.34 \%$. Considering that the K-type thermocouples used in the experiment had measuring errors and that the thermocouples that were inserted into the stack would damage the original gas channels and affect the temperature distribution, this level of errors was acceptable.

Thus far, the proposed model has been validated in terms of electrical properties and temperature distribution. The validation results show that this model is qualified as an accurate description of the SOFC stack for further research.

\section{Description of SOFC efficiency optimization}

Optimization of the SOFC system includes two parts: temperature safety and efficiency maximization. To guarantee the safe operation of the SOFC system, the stack and burner must satisfy certain temperature constraints. On the basis of temperature safety, the system efficiency is expected to be a maximum by determining the optimal operating parameters. The system efficiency is related closely to the power generated by the stack and to the energy consumed by the blower. Burner temperature control is relatively easy compared with that of the stack. Therefore, the stack and blower are mainly considered here for efficiency optimization. Temperature safety will be considered further in system control based on the optimization result.

In the following section, the efficiency optimization problem will be detailed in three parts: operating parameters, temperature constraints and efficiency maximization.

\section{(a) Operating parameters}

The main operating parameters of the SOFC stack are current $\left(I_{t o t}\right)$, inlet air 
temperature $\left(T_{\text {air }}^{\text {in }}\right)$, inlet fuel temperature $\left(T_{\text {fuel }}^{\text {in }}\right)$, inlet air flow rate $\left(F_{\text {air }}^{\text {in }}\right)$ and inlet fuel flow rate $\left(F_{\text {fuel }}^{\text {in }}\right)$.

To reflect the relationship between total gas flow and the gas consumed in an electrochemical reaction, the fuel utilization ratio $(F U)$ and air excess ratio $(A R)$ are defined as:

$$
F U=\frac{R_{f u e l}}{F_{\text {fuel }}^{\text {in }}}=\frac{n \times I_{\text {tot }}}{2 F \times F_{\text {fuel }}^{\text {in }}}
$$

where $R_{\text {fuel }}$ is the reaction mole rate of fuel and $F_{\text {fuel }}^{\text {in }}$ is the mole flow rate of the stack inlet fuel. $n$ is the number of single cells in the stack, $I_{t o t}$ is total current in the stack and $F$ is the Fnaraday constant.

$$
A R=\frac{F_{O_{2}}^{i n}}{R_{O_{2}}}=\frac{4 F \times x_{O_{2}} \times F_{a i r}^{i n}}{n \times I_{t o t}}
$$

where $F_{O_{2}}^{i n}$ is the mole flow rate of stack inlet oxygen and $R_{O_{2}}$ is the reaction mole rate of fuel. $F_{a i r}^{\text {in }}$ is the mole flow rate of stack inlet air and $x_{\mathrm{O}_{2}}$ is mole fraction of oxygen in the air.

After the definition of $F U$ and $A R$, the stack operating parameters are determined as $\left(I_{\text {tot }}, A R, F U, T_{\text {air }}^{\text {in }}, T_{\text {fuel }}^{\text {in }}\right) . I_{\text {tot }}$ was $40 \mathrm{~A}, 60 \mathrm{~A}$ and $80 \mathrm{~A}$ because the stack consisted of $13010 \mathrm{~cm} \times 10 \mathrm{~cm}$ single cells, which were designed for a $5-\mathrm{kW}$ power output, and its net power at $40 \mathrm{~A}, 60 \mathrm{~A}$ and $80 \mathrm{~A}$ corresponds to three typical operation conditions of low power $(3 \mathrm{~kW})$, high power $(5 \mathrm{~kW})$ and ultra-high power $(7 \mathrm{~kW})$, respectively. $A R$ ranges between 6 and 12 in $[13,14] . F U$ is between 0.6 and 0.9 in [13]. Because fuel recovery will be considered later in this paper, the $F U$ lies between 0.4 and 0.9 . The stack inlet gas temperature should not be too low nor too 
high when the electrochemical reaction and stack temperature control are taken into account. Therefore, $T_{\text {air }}^{\text {in }}$ and $T_{\text {fuel }}^{\text {in }}$ are limited to between $800 \mathrm{~K}$ and $1000 \mathrm{~K}$.

In summary, the ranges of the SOFC stack operating parameters as determined from Eq. (3) are:

$$
\begin{aligned}
& 6 \leq A R \leq 12 \\
& 0.4 \leq F U \leq 0.9 \\
& 800 K \leq T_{\text {air }}^{\text {in }} \leq 1000 K \\
& 800 K \leq T_{\text {fuel }}^{\text {in }} \leq 1000 K
\end{aligned}
$$

These value ranges are not absolute, but they appear to be reasonable references from a comprehensive analysis.

\section{(b) Temperature constraints}

To guarantee operational safety and good performance, the temperature distribution in the SOFC stack must satisfy certain constraints. The stack maximum temperature gradient $\left(T_{g r d_{-} \max }\right)$ and maximum temperature $\left(T_{\max }\right)$ are two important temperature safety indices that are used to describe the stack temperature distribution. $T_{\text {grd_max }}$ and $T_{\max }$ of the cross-flow stack are calculated as follows.

Because the fuel and air flow along two vertical directions in the cross-flow stack, the temperature gradients also should be calculated from the two directions in Fig. 5 according to:

$$
\begin{aligned}
& T_{\text {grd_air }}^{(i \quad i+1)}=\frac{\left|T_{\text {sol }}^{(i, j)}-T_{\text {sol }}^{(i, j+1)}\right|}{\frac{W_{\text {cell }}}{m}}(1 \leq i \leq m-1,1 \leq j \leq n) \\
& T_{\text {grd }_{-} \text {fuel }}^{(i+1)}=\frac{\left|T_{\text {sol }}^{(i j)}-T_{\text {sol }}^{(i, j+1)}\right|}{\frac{L_{\text {cell }}}{m}}(1 \leq i \leq m, 1 \leq j \leq n-1)
\end{aligned}
$$

Equation (4a) is used to calculate temperature gradients between nodes in the air 
flow direction whereas Eq. (4b) is used to obtain temperature gradients in the fuel flow direction. The maximum temperature gradient of the stack is obtained from the maximum value of the gradients as Eq. (5):

$$
T_{\text {grd_max }}=\max _{i, j}\left\{T_{\text {grd_air }}^{\left(\begin{array}{lll}
i+1 & j
\end{array}\right)}, T_{\text {grd_fuel }}^{\left(\begin{array}{lll}
i & j+1
\end{array}\right)}\right\}
$$

where $\max _{i, j}$ is the maximum value among all combinations of variables $i$ and $j$.

The stack maximum temperature is calculated from Eq. (6).

$$
\left.T_{\max }=\max _{i, j}\left\{T_{\text {sol }}^{(i} j\right)\right\}
$$

$T_{g r d_{-} \max }$ and $T_{\max }$ refer to the temperature of the solid structures in the stack.

In [28] and [29], the operating limit for the maximum temperature gradient is set at $8 \mathrm{Kcm}^{-1}$ and $10 \mathrm{Kcm}^{-1}$, respectively. In [13, 14, 28], the maximum temperature that the SOFC can tolerate is set at $1173 \mathrm{~K}$. We select Eq. (7) as the safety constraints under steady state and transient operation.

$$
\begin{aligned}
& T_{g r d_{-} \max } \leq 10 \mathrm{Kcm}^{-1} \\
& T_{\text {max }} \leq 1173 \mathrm{~K}
\end{aligned}
$$

\section{(c) Efficiency maximization}

The SOFC can convert chemical energy into electrical energy. The ratio of this energy conversion is termed the power generation efficiency and is defined as:

$$
\eta=\frac{V_{s t} \times I_{t o t}-P_{b l}}{F_{\text {fuel }}^{\text {in }} \times L H V_{\mathrm{H}_{2}}} \times 100 \%
$$

where $L H V_{H_{2}}$ is the low calorific value of hydrogen $\left(241.83 \mathrm{~kJ} \mathrm{~mol}^{-1}\right), V_{s t}$ is the total voltage of the SOFC stack and $P_{b l}$ is the power of the blower.

The power of the blower is proportional to the air flow rate and is described as:

$$
P_{b l}=C_{b l} \times F_{a i r}^{i n}
$$


The coefficient $C_{b l}$ is calculated from Eq. (10):

$$
C_{b l}=\frac{C_{p, a i r} T_{a i r, i n}}{\eta_{b l}}\left[\left(\frac{P_{b l}^{o u t}}{P_{b l}^{i n}}\right)^{\frac{\gamma-1}{\lambda}}-1\right]
$$

where $C_{p, a i r}$ is the specific heat capacity of air at constant pressure, $\eta_{b l}$ is the blower efficiency, $\lambda$ is the specific heat ratio of air (the value is 1.4 under an ideal gas assumption), $\quad T_{a i r, i n}$ is the air temperature before it enters the blower and $P_{b l}^{i n}$ and $P_{b l}^{\text {out }}$ are the gas pressures at the blower inlet and outlet, respectively.

Based on the above definition, the system efficiency optimization can be described as:

$$
\operatorname{Max} \eta(x)
$$

$$
\begin{aligned}
& \text { s.t. } \\
& \text { (1) } x \in\left\{\begin{array}{l|l}
\left(A R, F U, T_{\text {air }}^{\text {in }}, T_{\text {fuel }}^{\text {in }}\right) & \begin{array}{l}
6 \leq A R \leq 12 \\
0.4 \leq F U \leq 0.9 \\
800 K \leq T_{\text {air }}^{\text {in }} \leq 1000 K \\
800 K \leq T_{\text {air }}^{\text {in }} \leq 1000 K
\end{array}
\end{array}\right\} \\
& \text { (2) } T_{\text {grd_max }}(x) \leq 10 \mathrm{Kcm}^{-1} \text { and } T_{\text {max }}(x) \leq 1173 \mathrm{~K}
\end{aligned}
$$

where $\eta$ is the system efficiency as defined in Eq. (8).

\section{Analysis-based efficiency optimization}

The traverse optimization method was used in [13-15] to solve the optimization problem. Firstly, the operating parameters were discretized into a certain number of operating points in their value ranges. Their optimal operating points were determined by traverse optimization. A characteristic of this method is the comparison of all discrete operating points.

Based on the traverse optimization method in the literature, an analysis-based efficiency optimization method is proposed. This method consists of two select 
processes and one analysis process. A preliminary optimization is given firstly by traverse optimization. An analysis is conducted based on the preliminary optimization result to reduce the possible value ranges of the OOP candidates. The analysis will help to determine the required discrete precision of each operating parameter. Finally, secondary optimization will be done by the same traverse optimization process. The core of this new optimization method is the analysis process. The proposed optimization method is detailed in the following section.

\subsection{Preliminary optimization}

To solve the efficiency optimization problem in Eq. (11), the operating parameters were discretized in their value ranges into an operating point set as described by Eq. (12). The discrete precision of the different operating parameters were chosen by experience.

$$
P=\left\{\begin{array}{l|l}
\left(A R, F U, T_{\text {air }}^{i n}, T_{\text {fuel }}^{i n}\right) & \begin{array}{l}
A R \in\{x \mid x=6+k, 0 \leq k \leq 6, k \in N\}, \\
F U \in\{x \mid x=0.4+0.1 k, 0 \leq k \leq 5, k \in N\} \\
T_{\text {air }}^{i n} \in\{x \mid x=800+40 k, 0 \leq k \leq 5, k \in N\}, \\
T_{\text {fuel }}^{\text {in }} \in\{x \mid x=800+40 k, 0 \leq k \leq 5, k \in N\}
\end{array}
\end{array}\right\}
$$

where $N$ refers to the natural number set and $a \in A$ means that the element $a$ belongs to set $A$. There are $7 \times 6 \times 6 \times 6=1512$ operating points in set $P$ for different currents.

The OOPs under different currents are selected and shown in Table 3 . The $40 \mathrm{~A}, 60 \mathrm{~A}$ and $80 \mathrm{~A}$ correspond to net power levels of $3 \mathrm{~kW}, 5 \mathrm{~kW}$ and $7 \mathrm{~kW}$, respectively. Table 3 also shows that the efficiency is positively rated with $F U$. To obtain a high efficiency, the stack must operate under high $F U$. However, a high $F U$ can easily 
cause fuel starvation and make the stack unable to satisfy its temperature constraints. To overcome this contradiction, fuel recovery will be considered in the system structure design.

Although optimal operating points have been identified in Table 3, two underlying problems still need to be solved. Firstly, it has not been proven that the discrete precision in Eq. (12) is sufficiently dense to approximate the continuous situation. Secondly, the mechanism of how stack operating parameters affect the temperature distribution has not been determined, which would provide important guidance for SOFC system temperature control.

\subsection{Analysis of temperature and efficiency}

In this section, ANNs will be introduced to analyze the influence of operating parameters on the stack temperature distribution and system efficiency.

\subsubsection{ANN model identification}

The stack inlet conditions ( $A R, F U, T_{\text {air }}^{\text {in }}, T_{\text {fuel }}^{\text {in }}$ ) could be adjusted to set $T_{\max }$ and $T_{\text {grd_max }}$ within their constraints and to obtain maximum efficiency for certain currents as long as we know the mechanism of how stack inlet conditions affect the stack temperature distribution and system efficiency. The differential model is a full and complete description of this influencing mechanism, but it is too complicated to derive an analytical relationship between them. Therefore, an algebraic identification model is required.

Among the algebraic models, ANN models have good adaptability for a complex system [30], fault tolerance and good robustness. The radial basis function (RBF) and 
back propagation are frequently-used ANN algorithms in SOFC modeling. RBF has a faster identification speed and is more appropriate for online use. However, much time has to be spent on choosing the optimum initial values of the RBF neural network model parameters [31]. Because offline models are able to meet the requirements in this paper, a back propagation neural network is adopted in the identification process.

The ANN model of $\left(A R, F U, T_{\text {air }}^{\text {in }}, T_{\text {fuel }}^{\text {in }}\right)$ and $T_{g r d_{-} \max }$ for $40 \mathrm{~A}$ is taken as an example to detail the principle and process of ANN model identification. The purpose is to establish a function that can describe the relationship between these parameters accurately:

$$
T_{\text {grd_max }}=f\left(A R, F U, T_{\text {air }}^{\text {in }}, T_{\text {fuel }}^{\text {in }}\right)
$$

where the form of function $f$ and the parameters in $f$ will be identified by the simulation data of the differential model.

A detailed identification process is given in the appendix and the identification result is given by:

$$
y=B \times \tan \operatorname{sig}\left(A \times\left[\begin{array}{llll}
x_{1} & x_{2} & x_{3} & x_{4}
\end{array}\right]^{T}+b_{1}\right)+b_{2}
$$

where $x_{1}, x_{2}, x_{3}$ and $x_{4}$ are the normalized variables of $A R, F U, T_{\text {air }}^{\text {in }}$ and $T_{\text {fuel }}^{\text {in }}$ that are given by Eq. (A.2) in the appendix. $y$ is described by Eq. (A.3). The variable normalization process is explained in the appendix and is described explicitly by Eq. (A.1). The superscript $T$ represents the matrix transpose. 


$$
\begin{aligned}
A & =\left[\begin{array}{llll}
0.9435 & -0.0694 & -2.0460 & -0.0795 \\
0.1885 & 2.3650 & 0.0036 & 0.0424 \\
-0.9132 & 0.5278 & 0.2162 & 0.0114 \\
-0.3777 & 0.3132 & 0.3587 & 0.0152 \\
0.1542 & 0.0846 & 0.0802 & -0.0011 \\
0.1071 & 0.3124 & 0.0055 & 0.0697
\end{array}\right] \\
B & =\left[\begin{array}{llllll}
0.1772 & 0.1006 & 2.5542 & 0.6763 & -3.4001 & 1.8606
\end{array}\right] \\
b_{1} & =\left[\begin{array}{llllll}
-2.4075 & -2.1154 & -2.7953 & -0.8822 & 0.7759 & 0.9448
\end{array}\right]^{T} \\
b_{2} & =\left[\begin{array}{lllll}
3.7785
\end{array}\right]
\end{aligned}
$$

Other neural network models that are used later in temperature analysis and efficiency optimization have a three-layered structure. The number of neurons in the hidden layer of these models and their maximum and average errors are given in Table 4. Low-level errors in Table 4 prove the accuracy of these models and guaranteed the correctness of the analysis.

\subsubsection{Quantitative analysis}

Because $T_{\max }$ and $T_{g r d_{-} \max }$ are functions of operating parameters $\left(A R, F U, T_{\text {air }}^{\text {in }}, T_{\text {fuel }}^{\text {in }}\right)$, some conceptions based on the partial derivative of these functions are given in Eq. (15) to assist the analysis.

$$
\begin{aligned}
& F\left(T_{\text {max }}, x_{1}\right)=\frac{d T_{\text {max }}}{d x_{1}} \\
& F_{\text {max }}\left(T_{\text {max }}, x_{1}\right)=\max _{p_{0} \in p}\left(\left.\frac{d T_{\text {max }}}{d x_{1}}\right|_{p_{0}}\right) \\
& F_{\text {min }}\left(T_{\text {max }}, x_{1}\right)=\min _{p_{0} \in p}\left(\left.\frac{d T_{\text {max }}}{d x_{1}}\right|_{p_{0}}\right) \\
& \left.F_{\text {mean_abs }}\left(T_{\text {max }}, x_{1}\right)\right|_{p}=m_{p_{0} \in p}\left(a b s\left(\left.\frac{d T_{\text {max }}}{d x_{1}}\right|_{p_{0}}\right)\right)
\end{aligned}
$$


where $x_{1}, x_{2}, x_{3}$ and $x_{4}$ are the corresponding normalized variables of $A R$, $F U, T_{\text {air }}^{\text {in }}$ and $T_{\text {fuel }}^{\text {in }} . p_{0}$ refers to a certain operating point $\left(A R, F U, T_{\text {air }}^{\text {in }}, T_{\text {fuel }}^{\text {in }}\right)$ in set $P . \quad P$ is the set of all operating points described in Eq. (12). abs means solving the absolute value. mean indicates solving the average value.

The notation $F\left(T_{\max }, x_{1}\right)$ is the derivative of $T_{\max }$ with respect to $x_{1}$. $\left.F_{\text {max }}\left(T_{\text {max }}, x_{1}\right)\right|_{P}$ and $\left.F_{\text {min }}\left(T_{\text {max }}, x_{1}\right)\right|_{P}$ respectively, are the maximum and minimum values of $F\left(T_{\max }, x_{1}\right)$ on the set $P .\left.F_{\text {mean } a b s}\left(T_{\max }, x_{1}\right)\right|_{p}$ represents the average influence of $A R$ on $T_{\text {sol }}$ in the operating parameter set.

\section{(a) Temperature analysis}

Taking $60 \mathrm{~A}$ as an example, the influence of $\left(A R, F U, T_{\text {air }}^{\text {in }}, T_{\text {fuel }}^{\text {in }}\right)$ on $T_{\max }$ and $T_{\text {grd_max }}$ is shown in Tables 5 and 6, respectively. Table 5 shows that the maximum and minimum of $F\left(T_{\max }, x_{1}\right)$ on set $P$ are -26.0047 and -316.8484 , respectively. $F\left(T_{\max }, x_{1}\right)$ is negative, which means that $T_{\max }$ is related negatively to $A R$. Other data in Table 6 show that $T_{\max }$ is related positively to $F U, T_{a i r}^{i n}$ and $T_{\text {fuel }}^{\text {in }}$. As mentioned previously, the first column in Table 5 reflects the relative influencing power of the stack operating parameters on $T_{\max }$.

The influence of ( $\left.A R, F U, T_{\text {air }}^{\text {in }}, T_{\text {fuel }}^{\text {in }}\right)$ on $T_{g r d_{-} \max }$ can be determined from Table 5. $T_{\text {grd_max }}$ is related negatively with $A R$ and positively with $F U$ and $F_{\text {fuel }}^{\text {in }}$. The minimum value of $F\left(T_{g r d_{-} \max }, x_{3}\right)$ is -6.0573 , which corresponds to $x_{3}=-1$ $\left(T_{\text {air }}^{\text {in }}=800 \mathrm{~K}\right)$, and means that $T_{g r d_{-} \max }$ decreases firstly and then increases with increase in $T_{a i r}^{\text {in }}$. Therefore, the temperature of the stack inlet air should be increased appropriately to reduce $T_{\text {grd_max }}$. The minimum value of $F\left(T_{g r d_{-} \max }, x_{3}\right)$ is -1.023 
when $-1 \leq x_{3} \leq-0.2\left(800 K \leq T_{\text {air }}^{\text {in }} \leq 880 K\right)$. Therefore, $T_{\text {grd } \max }$ is related negatively with $T_{a i r}^{\text {in }}$ when $800 K \leq T_{a i r}^{\text {in }} \leq 880 K$.

Four conclusions obtained in the above analysis will be used directly in the later section. They are listed as follows:

(1) A smaller $T_{\text {fuel }}^{\text {in }}$ contributes to a smaller $T_{\max }$ and $T_{\text {grd_max }}$.

(2) $T_{g r d_{-} \max }$ is related negatively with $A R$.

(3) $T_{\text {grd_max }}$ and $T_{\max }$ are related positively with $F U$.

(4) When $T_{\text {air }}^{\text {in }}<880 \mathrm{~K}, T_{\text {grd_max }}$ is related negatively with $T_{\text {air }}^{\text {in }}$.

\section{(b) Efficiency analysis}

Taking the case of $60 \mathrm{~A}$ as an example, the effect of stack operating parameters (within temperature safety constraints) on efficiency $(\eta)$ is given in Table 7 . All the partial derivatives of $\eta$ with respect to $A R$ are negative. All the partial derivatives of $\eta$ with respect to $F U$ are positive. $\eta$ changes monotonously for $A R$ and $F U$. Therefore, only one optimal operating point exists on those dimensions.

If we assume that there is another operating point $\left((A R)_{0},(F U)_{0},\left(T_{\text {air }}^{i n}\right)_{0}\right.$, $\left.\left(T_{\text {fuel }}^{\text {in }}\right)_{0}\right)$ that could yield a higher efficiency than $(12,0.6,960 \mathrm{~K}, 880 \mathrm{~K})$ in Table 3, then the following holds:

$$
\begin{aligned}
& (A R)_{0} \leq 12 \\
& (F U)_{0} \leq 0.6
\end{aligned}
$$

In fact, the conclusions in Eq. (17) are also right as will be proven later.

$$
\begin{aligned}
& (A R)_{0}>11 \\
& (F U)_{0}<0.7 \\
& \left(T_{\text {air }}^{\text {in }}\right)>880 K
\end{aligned}
$$

Combining Eqs (16), (17) and (3) reduces the value ranges of the OOP 
candidates for $60 \mathrm{~A}$ to the region described in:

$$
\begin{aligned}
& 11 \leq A R \leq 12 \\
& 0.6 \leq F U \leq 0.7 \\
& 880 K \leq T_{\text {air }}^{\text {in }} \leq 1000 K \\
& 880 \mathrm{~K} \leq T_{\text {fuel }}^{\text {fi }} \leq 1000 \mathrm{~K}
\end{aligned}
$$

The region described by Eq. (18) is reduced to $2 \%$ of the original value region defined by (3) because the value ranges of $A R, F U$ and $T_{\text {air }}^{\text {in }}$ decrease to $1 / 6,1 / 5$ and $3 / 5$, respectively, of their original ranges.

In the following section, the three conclusions in (17) will be proven separately.

Proof I: $(A R)_{0}>11$

Firstly, $(A R)_{0}=11$ will be proven invalid. Then, $(A R)_{0}<11$ is also deduced invalid.

Proof by contradiction. Because a smaller $T_{\text {fuel }}^{\text {in }}$ contributes to a smaller $T_{\max }$ and $T_{\text {grd } \_ \text {max }}$, we assume that $(A R)_{0}=11$ and let $\left(T_{\text {fuel }}^{\text {in }}\right)_{0}=880 \mathrm{~K}$.

When $(A R)_{0}=11$ and $\left(T_{\text {fuel }}^{\text {in }}\right)_{0}=880 \mathrm{~K}$, the distribution of $T_{\text {grd } \max }$ and $T_{\max }$ under different combinations of $F U$ and $T_{a i r}^{i n}$ is shown in Fig. 6. The white regions in Fig. 7 are operating points that could allow the SOFC stack to satisfy the temperature constraints. In the temperature safety regions, $F U$ is already less than 0.55. Therefore, no operating points exist that could yield a higher efficiency than $\left(A R, F U, T_{\text {air }}^{\text {in }}, T_{\text {fuel }}^{\text {in }}\right)=(12,0.6,960 \mathrm{~K}, 880 \mathrm{~K})$ and guarantee the temperature safety of the SOFC stack when $(A R)_{0}=11$.

Because $T_{g r d_{-} \max }$ is related negatively with $A R$, the contours in the upper figure of Fig. 6 would move toward the upper left corner with decreasing $A R$. So, the $F U$ in the safety regions only could be lower. Therefore, $(A R)_{0}<11$ is also 
invalid.

In conclusion, $(A R)_{0}>11$ is proven.

Proof II: $F U<0.7$

Similarly, $(F U)_{0}=0.7$ is proven invalid, and $(F U)_{0}>0.7$ is deduced invalid too.

If we assume $(F U)_{0}=0.7$ and $\left(T_{\text {fuel }}^{i n}\right)_{0}=800 K$, the temperature distribution under the different combinations of $A R$ and $T_{a i r}^{i n}$ is shown in Fig. 8. The operating points resulted in $T_{g r d_{-} \max } \leq 10 \mathrm{Kcm}^{-1}$ existing in a small region in the right upper corner of the first figure in Fig. 8, whereas the operating points that satisfied $T_{\max } \leq 1173 \mathrm{~K}$ are distributed in the bottom right corner of the second figure in Fig. 8. These two parts have no intersection. Therefore, for $(F U)_{0}=0.7$ and $\left(T_{\text {fuel }}^{\text {in }}\right)_{0}=800 \mathrm{~K}$, the constraints of $T_{\text {grd } \max }$ and $T_{\max }$ cannot be guaranteed regardless of the values of $A R$ and $T_{a i r}^{i n}$.

Because $T_{g r d_{-} \max }$ and $T_{\max }$ are related positively with $F U$, the contours in Fig. 8 will move toward the upper right and lower right, respectively, when $(F U)_{0}>0.7$. Therefore, the operating points that satisfy $T_{g r d_{-} \max } \leq 10 \mathrm{Kcm}^{-1}$ and those points that satisfy $T_{\max } \leq 1173 K$ are even more unlikely to intersect.

Therefore, $F U<0.7$ is valid.

Proof III: $\left(T_{a i r}^{\text {in }}\right)_{0}>880 K$

If we assume that $\left(T_{\text {air }}^{i n}\right)_{0}=880 \mathrm{~K}$ and $\left(T_{\text {fuel }}^{i n}\right)_{0}=800 \mathrm{~K}$, the distribution of 
$T_{\text {grd_max }}$ under the different combinations of $A R$ and $F U$ is shown in Fig. 9. The $F U$ of operating points that satisfy $T_{g r d_{-} \max } \leq 10 \mathrm{Kcm}^{-1}$ are less than 0.5 and the $A R$ of these points is larger than 10.5. Therefore, safe operating points that have a higher efficiency than that of $\left(A R, F U, T_{\text {air }}^{\text {in }}, T_{\text {fuel }}^{\text {in }}\right)=(12,0.6,960 \mathrm{~K}, 880 \mathrm{~K})$ do not exist for $\left(T_{\text {air }}^{\text {in }}\right)_{0}=880 \mathrm{~K}$ and $\left(T_{\text {air }}^{\text {in }}\right)_{0}=880 \mathrm{~K}$ is invalid.

When $T_{\text {air }}^{i n}<880 K, T_{\text {grd_max }}$ is related negatively with $T_{\text {air }}^{i n}$. The contours in Fig. 9 move to the right lower corner if $T_{\text {air }}^{\text {in }}$ decreases for $T_{\text {air }}^{i n}<880 \mathrm{~K}$, which makes the efficiency lower than the former operating points.

In summary, $\left(T_{\text {air }}^{\text {in }}\right)_{0}>880 \mathrm{~K}$ is valid.

\subsection{Secondary optimization}

Because the discrete precision of the preliminary optimization may not be sufficiently high to approximate the continuous situation, secondary efficiency optimization is required for the reduced value ranges of the OOP candidates in Eq. (18). According to the influence of the different operating parameters on efficiency in the first column of Table 7, the value of the stack operating parameters in Eq. (18) can be discretized to:

$$
P_{L}=\left\{\begin{array}{l|l}
\left(A R, F U, T_{\text {air }}^{\text {in }}, T_{\text {fuel }}^{\text {in }}\right) & \begin{array}{l}
A R \in\{x \mid x=11+0.5 k, 0<k \leq 2, k \in N\}, \\
F U \in\{x \mid x=0.6+0.01 k, 0<k \leq 10, k \in N\}, \\
T_{\text {air }}^{\text {in }} \in\{x \mid x=880+30 k, 0<k \leq 4, k \in N\}, \\
T_{\text {fuel }}^{\text {in }} \in\{x \mid x=880+30 k, 0<k \leq 4, k \in N\},
\end{array}
\end{array}\right\}
$$

where $P_{L}$ refers to an operating parameter set that is defined on the local region.

The discrete densities of $A R, F U, T_{\text {air }}^{\text {in }}$ and $T_{\text {fuel }}^{\text {in }}$ become 2, 10,4/3 and 1 times, respectively, their original densities from Eq. (19). Table 7 shows that the 
influence of $F U$ on efficiency is largest, whereas the influence of $T_{\text {fuel }}^{\text {in }}$ on the efficiency is nearly negligible. That is why the density of $F U$ changes to 10 times its original value and the density of $T_{\text {fuel }}^{\text {in }}$ remains constant. If the original value region in Eq. (3) is discretized to such a density like Eq. (19), and all the operating points are compared by traverse optimization, a total of $13 \times 51 \times 8 \times 6=31824$ operating points exist. But only $7 \times 6 \times 6 \times 6+2 \times 10 \times 4 \times 6=1992$ operating points need to be considered. Therefore, the analysis-based efficiency optimization method proposed in this paper is deduced to be $93.7 \%$ of the workload. The OOPs for $40 \mathrm{~A}$ and $80 \mathrm{~A}$ are determined and are provided in Table 8 by the same method. Compared with the result in Table 3, optimal efficiencies are enhanced by $1.91 \%, 2.4 \%$ and $4.61 \%$ for $40 \mathrm{~A}, 60 \mathrm{~A}$ and $80 \mathrm{~A}$, respectively.

A diagram of the proposed efficiency optimization method is given in Fig. 10. The optimization process is composed of the "Select process" in the red block and the "Analysis process" in the green block. The "Select process" is similar to traverse optimization in the literature and the "Analysis process" is key to reduce the workload.

\subsection{Consideration of temperature dynamic response}

Table 8 shows that the optimal operating points of the SOFC on steady states always exist around the boundaries of temperature constraints. To guarantee the stack temperature safety, a dynamic response of the stack temperature distribution is considered. Specifically, the current is changed from $40 \mathrm{~A}$ to $80 \mathrm{~A}$ at $10000 \mathrm{~s}$ and back to $60 \mathrm{~A}$ from $80 \mathrm{~A}$ at $20000 \mathrm{~s}$ uniformly. The current change rate during power 
switching is set to $1 \mathrm{As}^{-1}$. The gas transmission delay is chosen to be $3 \mathrm{~s}$. Other operating parameters refer to the optimized result in Table 8 . The response of stack temperatures is shown in Fig. 11.

Figure 11 shows that the response of $T_{\max }$ is smooth and within constraints but that $T_{g r d_{-} \max }$ exceeded its constraint. A negative overshoot of $T_{g r d_{-} \max }$ occurs when the current increases at $10000 \mathrm{~s}$ and a positive overshoot of $T_{g r d_{-} \max }$ occurs when the current decreases at 20000 s. This occurs because the SOFC stack will change gradually from a high-temperature operating environment to a lower-temperature environment after the current decreases. The heat in the stack should be removed by more air, or by air with a lower temperature. Regardless of an increase in air flow or a decrease in temperature, the solid structures around the stack air inlet will assume the maximum influence. Therefore, the temperatures in this region would decrease more rapidly than others. Because the temperatures around the stack air inlet are lowest and decrease most rapidly in the meantime, the temperature distribution becomes more non-uniform and a positive overshoot of $T_{g r d_{-} \max }$ occurs. Conversely, a negative overshoot occurs when the current increases.

To overcome the problem of a positive overshoot of $T_{\text {grd }}$ max , part of the efficiency is sacrificed in exchange for temperature safety. However, the overall efficiency will be enhanced by fuel recovery. Therefore, the temperature constraint on $T_{g r d_{-} \max }$ at steady state is reduced to $T_{g r d_{-} \max } \leq 9 \mathrm{Kcm}^{-1}$ from $T_{g r d_{-} \max } \leq 10 \mathrm{Kcm}^{-1}$. The SOFC system temperature constraints are rewritten as:

$$
\begin{aligned}
& T_{\max } \leq 1173 \mathrm{~K} \\
& T_{\text {grd_max }} \leq 9 \mathrm{Kcm}^{-1}
\end{aligned}
$$


The temperature constraints in Eq. (20) cannot be satisfied at $80 \mathrm{~A}$ for the operating parameter value ranges set in this paper. This explains why the temperature is unsafe when the SOFC system outputs an ultrahigh power. The optimal points under the temperature constraints in Eq. (20) are obtained and are given by Table 9.

\section{System control}

Thermal electrical cooperative control of the SOFC system is considered based on the former efficiency optimization. According to the optimization result, two requirements are proposed for the SOFC system control. Firstly, the stack should operate on a low single loop $F U$ to obtain a low $T_{\text {grd_max }}$. The overall system FU should be enhanced to obtain a high power-generating efficiency. Secondly, the inlet condition of the SOFC stack should be controllable, which guarantees the stack temperature safety and maximum efficiency. Because the existing system control in the literature cannot satisfy these two requirements, a novel SOFC system structure and corresponding control strategy are proposed. A key problem of the SOFC control is that fast load following, temperature safety, fuel starvation and efficiency promotion are solved simultaneously by the proposed control strategy based on the new system structure.

\subsection{System structure}

A new SOFC system structure with three gas bypasses and fuel recovery is proposed in this paper to enhance the overall fuel utilization and to control the inlet condition of the SOFC stack. The system structure is shown in Fig. 12.

The system consists of two blowers, two heat exchangers, three gas mixers, one 
SOFC stack, one catalytic burner, one condenser and three bypass valves. The gases in the operating SOFC system include hydrogen, air, flue gas, recycled fuel and exhausted gas. An air preheating bypass, a fuel preheating bypass and a fuel recovery bypass are contained in this system.

Air (A1) is blown to gas channel (A2) by the blower at ambient temperature and pressure. Part of the air (A3) will be preheated (A4) in an air heat exchanger by high-temperature flue gas. The other part of the air (A5) passes through the air bypass without being preheated. The two air streams are mixed (A6) before being fed into the stack.

Hydrogen (H1) is fed into the gas channel (H2) by a high-pressure gas cylinder. Similarly, part of the hydrogen $(\mathrm{H} 3)$ will be preheated $(\mathrm{H} 4)$ in the fuel heat exchanger by high-temperature flue gas and the other part of the hydrogen (H5) will pass though the fuel preheating bypass without being preheated. Two parts of the hydrogen are mixed (H6) before entering the stack.

The mixed air (A6) and hydrogen (H6) are fed into the cathode and anode of the SOFC stack, respectively. Electrochemical reactions between oxygen and hydrogen occur in the stack. The oxygen in the air and hydrogen in the fuel are consumed whereas water vapor is produced and is supplied to the fuel gases. The resultant fuel (H7) and air (A7) that exit the SOFC stack will have a higher temperature because of the exothermal reaction. Part of the remaining hydrogen in the fuel (H8) is burned in the burner to produce high-temperature flue gas (F1) that is used to preheat the low-temperature fuel and air. A large part of this fuel gas (F2) 
is used to preheat air and another small part (F3) is used to preheat fuel. The ratio between them is adjusted by using the bypass valves.

The other part of the remaining hydrogen (R1) is recovered through the fuel recovery bypass. The condenser is used to remove vapor from the recovered gas, to cool it down and to provide hot water. The temperature of the flue gas (R1) will decrease to $\sim 150^{\circ} \mathrm{C}$, which could be tolerated by the bypass valve and blower. The purified recovery gas (R2) passes though the fuel recovery bypass valve (R3) and is blown to the mixer 2 (R4) by the blower. This part of the fuel enters the stack to react again.

\subsection{Control strategy}

Based on the system structure in Fig. 12 and the temperature analysis and efficiency optimization in the former section, the following control strategy will be adopted.

1) Current-based control, which means adjusting the current to follow the external load power changes.

2) According to the current $I_{t o t}$ and optimization results, an appropriate $A R$, $F U$ and $B b$ are chosen. The air and fuel flow rates that enter the SOFC stack, namely $F_{\text {air }}^{\text {in }}$ and $F_{\text {fuel }}^{\text {in }}$, are calculated by combining $I_{\text {tot }}, A R, F U$ and $F b$. The gas flow rates are adjusted by feed-forward control because the relationship between the gas flow rates and the current is analytical and determinate.

3) The temperatures of the stack inlet air and fuel ( $T_{\text {air }}^{i n}$ and $\left.T_{\text {fuel }}^{\text {in }}\right)$ are controlled by $A b$ and $F b$, respectively. The burner temperature $\left(T_{b u r n e r}\right)$ is controlled by $B b$. Because only a qualitative relationship exists between the bypass valve opening ratio 
and the corresponding controlled temperature, feedback control was used to control $T_{\text {air }}^{\text {in }}, T_{\text {fuel }}^{\text {in }}$ and $T_{\text {burner }}$.

The diagram of the system control is shown in Fig. 13. The control strategy proposed in this paper does not depend on the specific control method.

\section{Feed forward control:}

The fuel entering stack ( $F_{\text {fuel,st }}^{\text {in }}$ ) consists of fuel that is provided by high-pressure gas cylinders $\left(F_{\text {fuel,sys }}^{\text {in }}\right)$ and those provided by fuel recovery $\left(F_{f u e l, r e}^{\text {in }}\right.$ ). The fuel flow rate provided by the gas cylinders can be calculated from:

$$
\begin{aligned}
F_{f u e l, s y s}^{i n} & =F_{f u e l, s t}^{i n}-F_{f u e l, r e}^{i n} \\
& =\frac{n \times I_{t o t}}{2 F \times F U}(1-(1-F U) \times B b)
\end{aligned}
$$

The flow rates of air that enters stack $\left(F_{\text {air }}^{\text {in }}\right)$ equals that of air that is provided by the air blower $\left(F_{a i r, s y s}^{\text {in }}\right)$. Therefore, the air flow rate provided by the blower is calculated from:

$$
F_{a i r, s y s}^{i n}=F_{a i r}^{i n}=\frac{n \times I_{t o t} \times A R}{4 F \times x_{O_{2}}}
$$

$A R$ and $F U$ on different $I_{t o t}$ is determined from the efficiency optimization result. $B b$ in Eq. (21) is calculated by following feedback control.

\section{Feedback control:}

$F b, A b$ and $B b$ are used to control $T_{\text {air }}^{\text {in }}, T_{\text {fuel }}^{\text {in }}$ and $T_{\text {burner }}$. Because no catalytic relationships exist between these variables, feedback control is assumed as a control approach.

Proportional-integral-derivative (PID) control is a basic and widely used control method, whereas sliding mode control is known for its robustness. Our 
controller combined advantages of both. PID is used to achieve precise control, and variable speed sliding mode control is used to achieve a rapid response and robustness. The controllers are described by:

$$
\Delta u=k_{s} \operatorname{sign}\left(T-T^{r e f}\right)+k_{p}\left(T-T^{r e f}\right)+k_{I} \int\left(T-T^{r e f}\right) d t+k_{D} \frac{d}{d t}\left(T-T^{r e f}\right)
$$

where $\Delta u$ refers to the controlling variables ( $F b, A b, B b), T$ represents the controlled variables $\left(T_{\text {air }}^{\text {in }}, T_{\text {fuel }}^{\text {in }}, T_{\text {burner }}\right)$ and $T^{\text {ref }}$ are the reference values of these controlled variables. $k_{p}, k_{I}$ and $k_{D}$ are the proportional, integral and derivative control, respectively. $k_{s}$ is the speed of the sliding mode control and is calculated from:

$$
k_{s}=\left(\frac{T-T^{r e f}}{2}\right)^{2}
$$

The speed of the sliding mode control is chosen as the square of half of the error.

When the absolute value of the error $\left|T-T^{r e f}\right|$ is larger than 2 , then $k_{s}>1$. The quadratic term magnifies $k_{s}$. When $\left|T-T^{r e f}\right|$ is smaller than $2, k_{s}<1$. The quadratic term will decrease $k_{s}$ rapidly and the control depends mainly on PID at this time.

The specific values of $k_{p}, k_{I}$ and $k_{D}$ in a different controller are given in Table 10.

\subsection{Simulation result and discussion}

To study the system dynamic process, the simulation will be switched between the optimal operating points in Table 9. Current was changed uniformly to 40 A from $60 \mathrm{~A}$ at $10000 \mathrm{~s}$ and changed back to $60 \mathrm{~A}$ at $20000 \mathrm{~s}$ at $1 \mathrm{As}^{-1}$. Other operating parameters refer to the optimized result in Table 9. In the following section, the 
simulation result will be analyzed in terms of fuel starvation, temperature safety, load following and efficiency promotion.

\section{(a) Fuel starvation}

During the power switch transients, the change rate of current is assumed to be $\Delta I\left(\mathrm{As}^{-1}\right)$ and the gas transmission delay is $t(\mathrm{~s})$. Before the switch, the original current is $I(\mathrm{~A})$ and the fuel utilization is $F U$. The condition to avoid fuel starvation can be described by:

$$
\frac{I}{F U} \geq I+t \times \Delta I
$$

Fuel starvation becomes a problem only when the current is increasing. Substituting the operating parameters in Table 9 into Eq. (25) yields the conditions to avoid fuel starvation at $40 \mathrm{~A}, 60 \mathrm{~A}$ and $80 \mathrm{~A}$ :

$$
\begin{aligned}
& 40 A: t \times \Delta I \leq 7.058 \\
& 60 A: t \times \Delta I \leq 32.3 \\
& 80 A: t \times \Delta I \leq 80
\end{aligned}
$$

Because the fuel utilization is as high as 0.85 at $40 \mathrm{~A}$, it is possible for fuel starvation to occur. Equation (26) indicates that if $t=7 \mathrm{~s}$ then $\Delta I$ should be smaller than $\sim 1 \mathrm{As}^{-1}$. No fuel starvation will occur in the power switch process in this paper.

\section{(b) Temperature safety}

As shown in Fig. 14, $T_{\text {fuel }}^{\text {in }}$ and $T_{\text {air }}^{\text {in }}$ could be controlled precisely whereas $T_{\text {burner }}$ has an overshoot that is less than $10 \mathrm{~K}$. Tref in Fig. 14 refers to the reference values of the corresponding temperature variables.

The response of $T_{\text {burner }}$ is shown in Fig. 15. The power decrease at $10000 \mathrm{~s}$ is shown in Fig. 15 (a) and the increase at $20000 \mathrm{~s}$ is shown in Fig. 15 (b). The control 
approach in this paper sped up the response and decreased the overshoots effectively.

The SOFC stack temperature is the core and hardest part of the system temperature control, as shown in Fig. 16. The overshoot of $T_{\max }$ is small and the change in $T_{\max }$ is constrained by $T_{\max } \leq 1173 \mathrm{~K}$. Because sufficient temperature safety redundancy has been provided to $T_{g d_{-} \max }$, the constraint $T_{\text {grd_max }} \leq 10 \mathrm{Kcm}^{-1}$ can be guaranteed as long as the optimal operating points in Table 9 are used.

Combining the results in Figs 14 (c) and 16 shows that the system temperature safety can be guaranteed either at steady state or during transients of the power switch.

\section{(c) Load following}

The results in Figs 17 and 18 show responses of the current and net power, respectively.

Figure 17 shows that the current is restored to steady state in less than $10 \mathrm{~s}$ and that the overshoot is small when the current tracks its reference values. This suggests that the electrochemical reaction is rapid and that the current-based control approach used in this paper is effective.

Figure 18 shows that a switch in system net power could be achieved in less than $40 \mathrm{~s}$. Therefore, rapid load following can be achieved by using the proposed control strategy.

\section{(d) Fuel utilization promotion}

Fuel recovery is used in the system structure design to enhance the overall fuel utilization. Of the fuel that enters the SOFC stack, $F U$ is used to generate electricity and $(1-F U) \times B b$ are recovered to react again. The remainder 
$((1-F U) \times(1-B b))$ will be burnt in the burner to provide heat for the heat exchangers.

A single loop $F U$ and overall $F U$ are compared in Fig. 19. The fuel utilization ratio is promoted by fuel recovery. Because the SOFC stack operating temperature at $60 \mathrm{~A}$ is higher than the operating temperature at $40 \mathrm{~A}$, only a small part of the exhausted fuel needs to be burnt for gas preheating and more fuel could be recovered. So, the overall $F U$ is higher for a larger current.

The temperature safety, load following, efficiency optimization and fuel starvation of SOFC system could be solved simultaneously by using the control strategy based on the proposed new system structure.

\section{Conclusions}

In this work, modeling, analysis and optimization were conducted for a 5-kW cross-flow SOFC system. A novel system structure and control strategy were proposed to achieve thermal electrical cooperative control of the SOFC system.

An analysis-based optimization method was proposed to optimize the efficiency of the SOFC system. During the optimization, ANN models as identified from the simulation data of the validated SOFC differential model were used as an analysis tool. The efficiency analysis provided a basis to determine the required discrete precision of each operating parameter. The possible value ranges of the OOP candidates were reduced significantly by combining preliminary optimization results and thermal analysis. Compared with traverse optimization in literature, the analysis-based optimization method proposed in this paper could save more than 
$90 \%$ of the workload.

According to the efficiency optimization results, a low single loop fuel utilization ratio and adjustable stack inlet condition were required for system control. Therefore, a new system structure and a stack inlet condition-based control strategy were proposed to achieve temperature safety and high efficiency in steady state and with power switching transients. Fuel recovery was used in the new system structure to enhance the overall fuel utilization, and gas bypasses were used to control the stack inlet gas temperature accurately. The control strategy combined current-based feed forward control and error-based feedback control. Key problems of the system control, which include temperature safety, fast load following, fuel starvation and efficiency promotion, were considered. The simulation results prove that the work in this paper is effective.

\section{Acknowledgments}

This work is supported by the National science Foundation of China (61403151, 61573162) and Hubei Province Key Technology R\&D Program (2015BCE059).

\section{Appendix A. Detail of ANN model identification}

The identifying process will be demonstrated from data preparation and model structure selection.

\section{(a) Data preparation}

The data used in the ANN model identification were obtained from the 
simulation results of the validated 2D differential model. A total of 1512 corresponding outputs $\left(T_{g r d_{-} \max }\right)$ would be obtained by simulating the differential model on 1512 operating parameters in Eq. (12) at $40 \mathrm{~A}$.

The data should be reordered randomly and normalized firstly. Randomization of all data was done to make the training process converge faster. Normalization would map all inputs to a value between -1 and 1 . Because the value ranges of these inputs differed significantly, normalization was implemented to weaken its influence on the training process. Otherwise, variables with large value ranges (such as $T_{a i r}^{i n}$ and $T_{\text {fuel }}^{i n}$ ) yield a greater weight than those with small value ranges (such as $F U$ ).

Normalization reflects a variable $X$ into a variable $x$ between -1 and 1 . The specific methods are described by:

$$
x=\frac{X-\frac{X_{\text {max }}+X_{\text {min }}}{2}}{\frac{X_{\text {max }}+X_{\text {min }}}{2}}
$$

where $X_{\max }$ and $X_{\min }$ represent the maximum and minimum values of $X$, respectively.

By considering the set value ranges of $\left(A R, F U, F_{a i r}^{i n}, F_{f u e l}^{i n}\right)$ in Eq. (3), a normalization of the input variables is achieved:

$$
\left[\begin{array}{l}
x_{1} \\
x_{2} \\
x_{3} \\
x_{4}
\end{array}\right]=\left[\begin{array}{c}
\frac{A R-9}{6} \\
\frac{F U-0.65}{0.25} \\
\frac{T_{\text {air }}^{\text {in }}-900}{100} \\
\frac{T_{\text {fuel }}^{\text {in }}-900}{100}
\end{array}\right]
$$

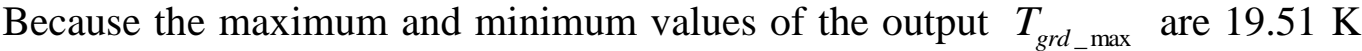


$\mathrm{cm}^{-1}$ and $6.43 \mathrm{~K} \mathrm{~cm}^{-1}$, respectively, its normalization is:

$$
y=\frac{T_{g r d_{-} \max }-12.925}{6.585}
$$

The processed data set was divided into three subsets: a training, cross-validation and test set. The training set is used to train the neural network. The cross-validation set ensures that the network does not become over-trained. The training is stopped when the error of the trained model on the cross-validation set starts to increase. The testing set, which is not used during the training, is used after training to examine the generalization capabilities of the network and to compare with the other errors (training error and cross-validation error). All three errors should be similar [32].

\section{(b) Model structure selection}

The structure of a neural network refers to the number of layers in the network and the neurons in each layer. If the number of layers and neurons in each layer is insufficient, the identified model will not have sufficient complexity to describe the non-linearity of the SOFC, which is termed underfitting. If less identification data is available and if the ANN structure is too complex, the non-linearity of the identified model will exceed the non-linearity of the actual SOFC system, which is termed overfitting. In this case, an identified model will have a very small error on the training data but a large error on the test set. Thus, the identified model is unable to be generalized. Therefore, the non-linearity of the object and the size of identification data should be considered to select an appropriate ANN structure.

With 2625 identification data, a $5 \times 11 \times 6$ structure (three layers, five neurons in the input layer, 11 neurons in the hidden layer and six neurons in the output layer) was 
used in [33]. We chose a neural network with three layers because 1512 identification data exist and over fitting has appeared on the model with four layers. Because four inputs and one output exists in our case, the specific structure of the ANN model with three layers is $4 \times n \times 1$, where $n$ is the number of neurons in the hidden layer. The identification errors from $n=4$ to $n=7$ are shown in Table A.1. The cases for $n>7$ are not given here, because overfitting occurred when $n=7$. Table 4 shows that the maximum error of the identified ANN model is less than $0.25 \mathrm{~K} \mathrm{~cm}^{-1}$ and its average error is almost negligible.

Because the model performs best when $n=6$, the final structure of the neural network is chosen as $4 \times 6 \times 1$ as shown in Fig. A.1. $\Sigma$ in Fig. A.1 means the weighed sum (the weight between different layers are parameters to be identified). Tf is the hyperbolic tangent function, $L f$ is the linear function and $T f(x)=\tan \operatorname{sig}(x)$ and $L f(x)=x$.

Because the maximum error of the identified model on the 1512 discrete operating points is $0.2123 \mathrm{~K} \mathrm{~cm}^{-1}$, the identified ANN model can be used to describe the relationship between $\left(A R, F U, F_{\text {air }}^{\text {in }}, F_{\text {fuel }}^{\text {in }}\right)$ and $T_{g r d_{-} \max }$ at $40 \mathrm{~A}$.

\section{References}

[1] H. Apfel, M. Rzepka, H. Tu, U. Stimming. Thermal start-up behavior and thermal management of SOFC's. J Power Sources 2006; 154; 370-378.

[2] Chiang LK, Liu HC, Shiu YH, Lee CH, Lee RY. Thermo-electrochemical and thermal stress analysis for an anode-supported SOFC cell. Renew Energ 2008; 33; 2508-2588. 
[3] Azra S, Miriam K, Tord T, Mohsen A. Steady state and transient thermal stress analysis in planar solid oxide fuel cells. J power Sources 2005; 145; 463-469.

[4] Lin CK, Chen TT, Chyou YP, Chiang LK. Thermal stress analysis of a planar SOFC stack. J Power Sources 2007; 164; 138-251.

[5] Mike P, Kerry M, Vince S, Larry C, Gary M. Demonstration of a highly efficient solid oxide fuel cell power system using adiabatic steam reforming and anode gas recirculation. J Power Sources 2012; 205; 377-384.

[6] Fabian M, Faryar J, Robert G, Jacob B. Novel solid oxide fuel cell system controller for rapid load following. J Power Sources 2007; 172; 308-323.

[7] H. Yakabe, T. Ogiwara, M. Hishinuma, I. Yasuda. 3-D model calculation for planar SOFC. J Power Source 2001; 102; 144-154.

[8] K. P. Recknagel, R. E. Williford, L. A. Chick, D. R. Rector, M. A. Khaleel. Three-dimensional thermos-fluid electrochemical modeling of planar SOFC stacks. J Power Source 2003; 113; 109-144.

[9] M. Iwata, T. Hikosaka, et al. Performance analysis of planar-type unit SOFC considering current and temperature distributions. Solid State Ionics 2000; 132; 297-308.

[10] S. Campanari, P. Lora. Comparison of finite volume SOFC models for the simulation of a planar cell geometry. Fell Cells 2005; 5; 34-51.

[11] L. K. Chiang, H. C. Liu, et al. Thermo-electrochemical and thermal stress analysis for an anode-supported SOFC cell. Renewable Energy 2008; 33; 2580-2588. 
[12] Cao HL. Dynamic modeling and control of solid oxide fuel cell systems [Doctoral thesis]. Huazhong University of Science and Technology 2012.

[13] H. Xi. Dynamic modeling and control of planar SOFC power systems. [Doctoral thesis]. University of Michigan.

[14] J.H. Jiang. Dynamic modeling and control of planar solid oxide fuel cell systems [Doctoral thesis]. Huazhong University of Science and Technology 2013.

[15] L. Zhang. Control strategy for power management, efficiency-optimization and operating safety of a 5-kW solid oxide fuel cell system. Electrochimica Acta 2015; $177 ; 237-249$.

[16] Y. H. Li, S. S. Choi. An analysis of the control and Operation of a SOFC Power Plant in an Isolated System. IEEE TRANSACTIONS ON ENERGY CONVERSION. 2005 (20): 381-387.

[17] N. Akkinapragada, B. H. Chowdhury. SOFC-based Fuel Cells for Load Following Stationary Applications. 2006 38th North American Power Symposium. 2006: $553-560$.

[18] T.J. Zhang, G. Feng. Rapid Load Following of an SOFC Power System Via Stable Fuzzy Predictive Tracking Controller. IEEE TRANSACTIONS ON FUZZY SYSTEMS. 2009 (17): 357-371

[19] Y. Zhu, K. Tomsovic. Eevelopment of models for analyzing the load-following performance of microturbines and fuel cells $[\mathrm{J}]$. Electric Power Systems Research. 2002 (62): 1-11.

[20] E. Achenbach. Response of a solid oxide fuel cell to load change [J]. Journal of Power Sources. 1995 (57): 105-109. 
[21] C. Haynes. Simulating process settings for unslaved SOFC response to increases in load demand [J]. Journal of Power Sources. 2002 (109): 365-376.

[22] Y. Inui, N. Ito, T. Nakajima, et al. Analytical investigation on cell temperature control method of planar solid oxide fuel cell $[\mathrm{J}]$. Energy Conversion and Management, 2006, 47(15-16): 2319-2328.

[23] M. Fardadi, F. Mueller, F. Jabbari. Feedback control of solid oxide fuel cell spatial temperature variation $[\mathrm{J}]$. Journal of Power Sources, 2010, 195(13): $4222-4233$.

[24] S. Y. Jin, Jeong L. Sohn, Sung Tack Ro. Performance characteristics of part-load operations of a solid oxide fuel cell/gas turbine hybrid system using air-bypass. Journal of power sources. 2008 (175): 296-302.

[25] F. Calise, A. Palombo, L. Vanoli. Design and partial load exergy analysis of hybrid SOFC-GY power plant. Journal of power sources. 2006 (158): 225-244.

[26] Y.H. Zhu, Y.Z. Li, W.J. Cai. Control oriented modeling of ejector in anode gas recirculation solid oxygen fuel cell systems. Energy Conversion and Management. 2011 (52): 1881-1889.

[27] H. Cheng. A nonlinear sliding mode observer for the estimation of temperature distribution in a planar solid oxide fuel cell. Int J Hydrogen Energy 2015; 40; 593-606.

[28] M. Grötsch, M. Gundermann, et al. Development and experimental investigation of an extended Kalman filter for an industrial molten carbonate fuel cell system [J]. Journal of Process Control. 2006 (16): 985-992. 
[29] P. Aguiar, C. S. Adjiman, et al. Anode-supported intermediate temperature direct internal reforming solid oxide fuel cell I: mode-based steady-state performance [J]. Journal of Power Sources. 2004 (138): 120-136.

[30] D. F. Liu, G. Fu, Y. F. Liu. Optimal control for aluminum hydroxide calcinations based on fuzzy neural networks, In: 2009 International conference on energy and environment technology, Gui Lin, China; 2009; 443-446.

[31] X. J. Wu, X. J. Zhu, et al. Modeling a SOFC stack based on GA-RBF neural networks identification. J Power Sources 2007; 167; 145-150.

[32] X. J. Wu, X. J. Zhu, et al. Predictive control of SOFC based on a GA-RBF neural network model. Journal Power Sources 2008 (179): 232-239.

[33] O. Razbani, M. Assadi. Artificial neural network model of a short stack solid oxide fuel cell based on experimental data. Journal of Power Sources [J]. Journal of Power Sources, 2014 (246): 581-586. 


\section{Figure captions:}

Fig. 1 Cross flow SOFC stack: (a) working principle, (b) structure

Fig. 2 Diagram of finite volume division of SOFC stack

Fig.3 Model validation experiment: (a) test platform; (b) assembling form

Fig. 4 Testing and validation of cross flow SOFC stack

Fig. 5 Diagram of stack temperature gradients on air and fuel flow directions

Fig. 6 The stack temperature distribution on the condition that $(A R)_{0}=11$ and $\left(T_{\text {fuel }}^{\text {in }}\right)_{0}=800 \mathrm{~K}$

Fig. 7 The stack safety operating region on $(A R)_{0}=11$ and $\left(T_{\text {fuel }}^{\text {in }}\right)_{0}=800 \mathrm{~K}$

Fig. 8 The stack temperature distribution on the condition that $(F U)_{0}=0.7$ and $\left(T_{\text {fuel }}^{\text {in }}\right)_{0}=800 \mathrm{~K}$

Fig. 9 The $T_{\text {grd_max }}$ on the condition that $\left(T_{\text {air }}^{\text {in }}\right)_{0}=880 \mathrm{~K}$ and $\left(T_{\text {fuel }}^{\text {in }}\right)_{0}=800 \mathrm{~K}$

Fig. 10 Diagram of the efficiency optimization process

Fig. 11 The system temperature dynamic response during power switch

Fig. 12 Diagram of SOFC system structure

Fig. 13 Diagram of system control strategy

Fig. 14 The dynamic responses of controlled temperatures

Fig. 15 The burner temperature: (a) during current decreasing, (b) during current increasing

Fig. 16 The stack temperature: (a) $T_{\text {max }}$, (b) $T_{g r d_{-} \max }$

Fig. 17 The responses of current: (a) overall, (b) decreasing, (c) increasing

Fig. 18 System net power switching process: (a) overall, (b) decreasing, (c) increasing

Fig. 19 Comparison of the single loop and overall fuel utilization

Fig. A.1 Diagram of ANN model structure 
Fig. 1

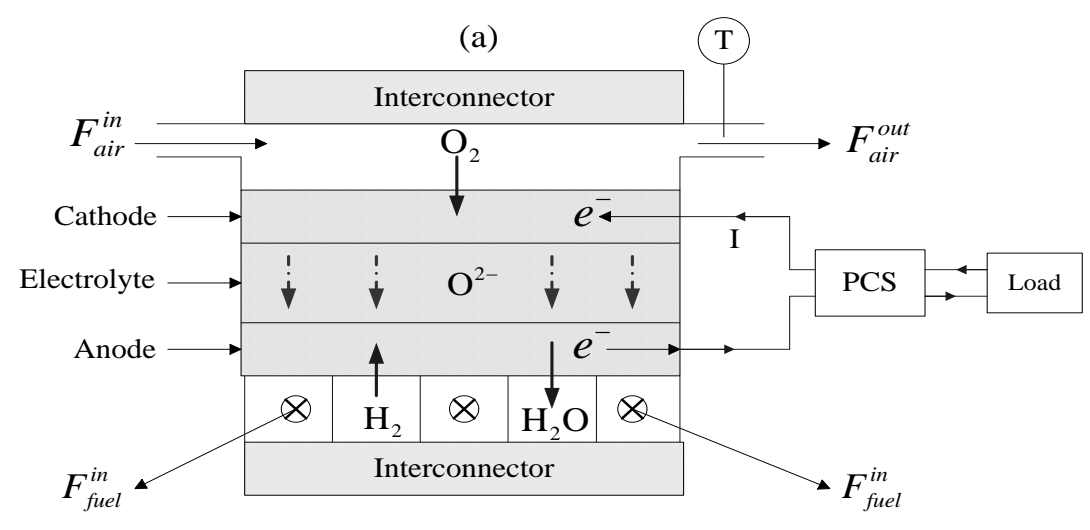

(b)

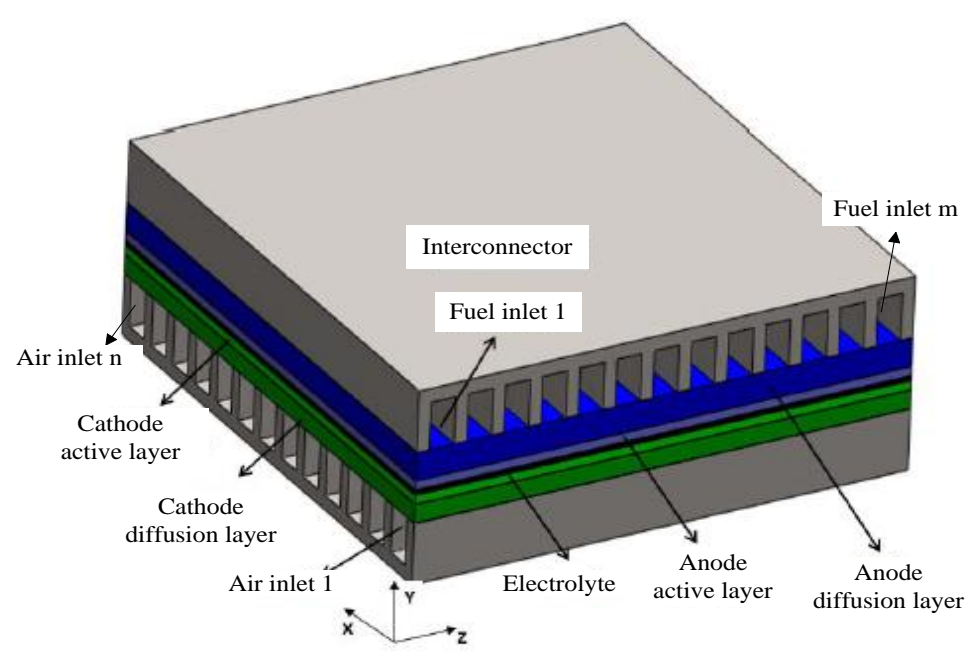


Fig. 2

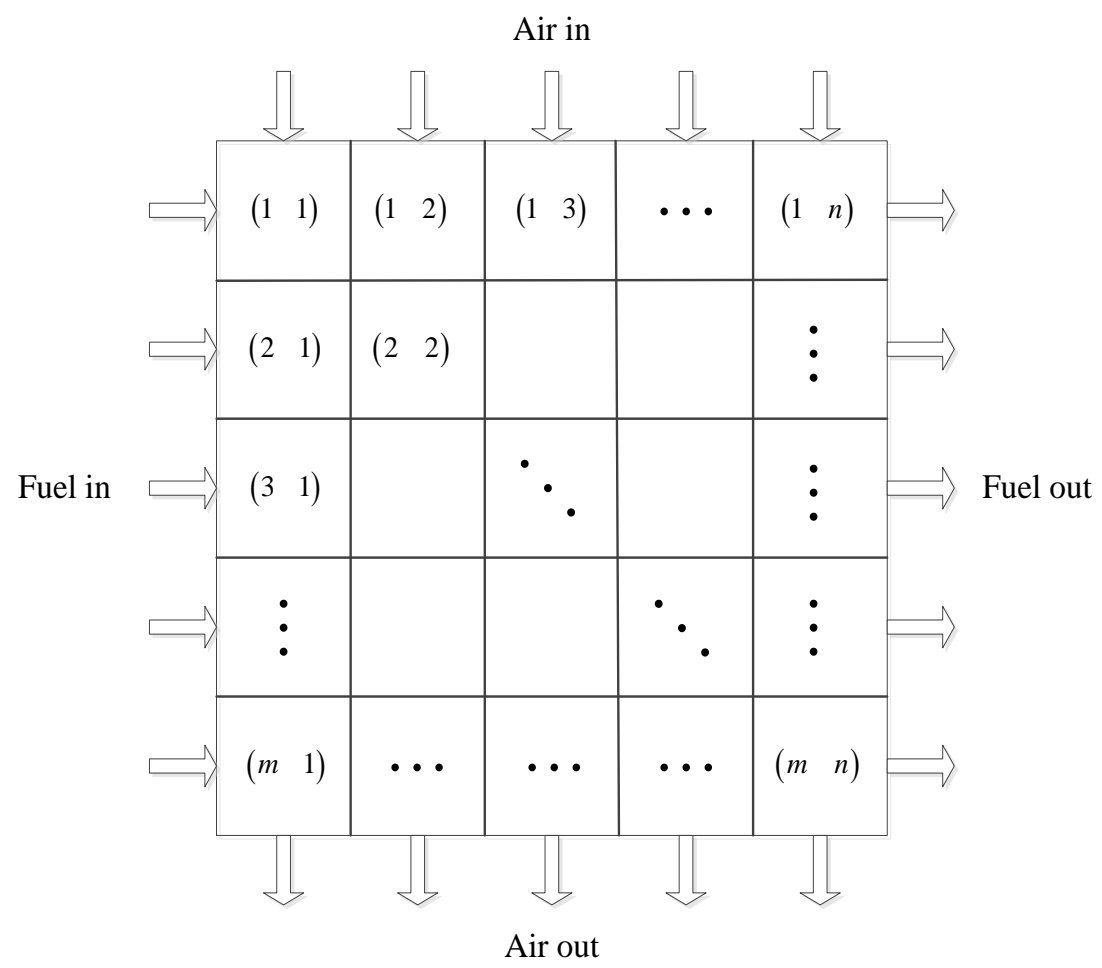


Fig. 3

(a)

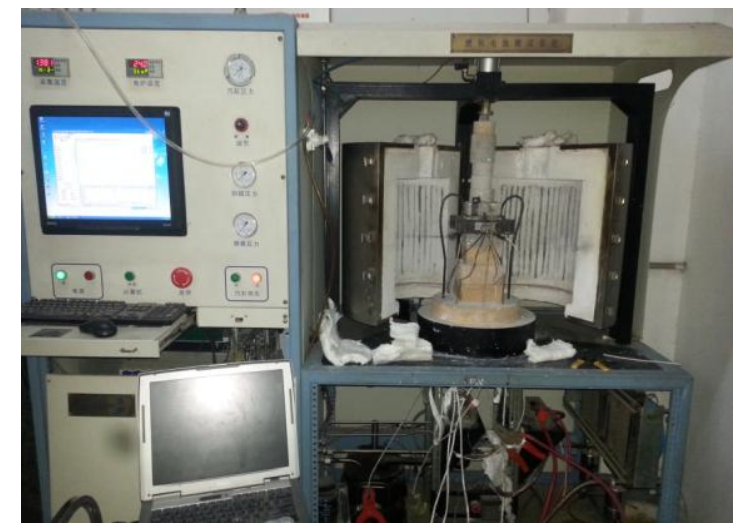

(b)

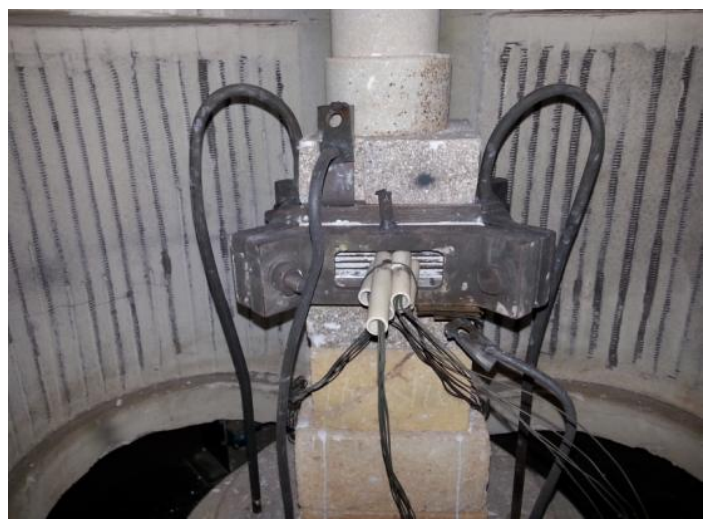


Fig. 4

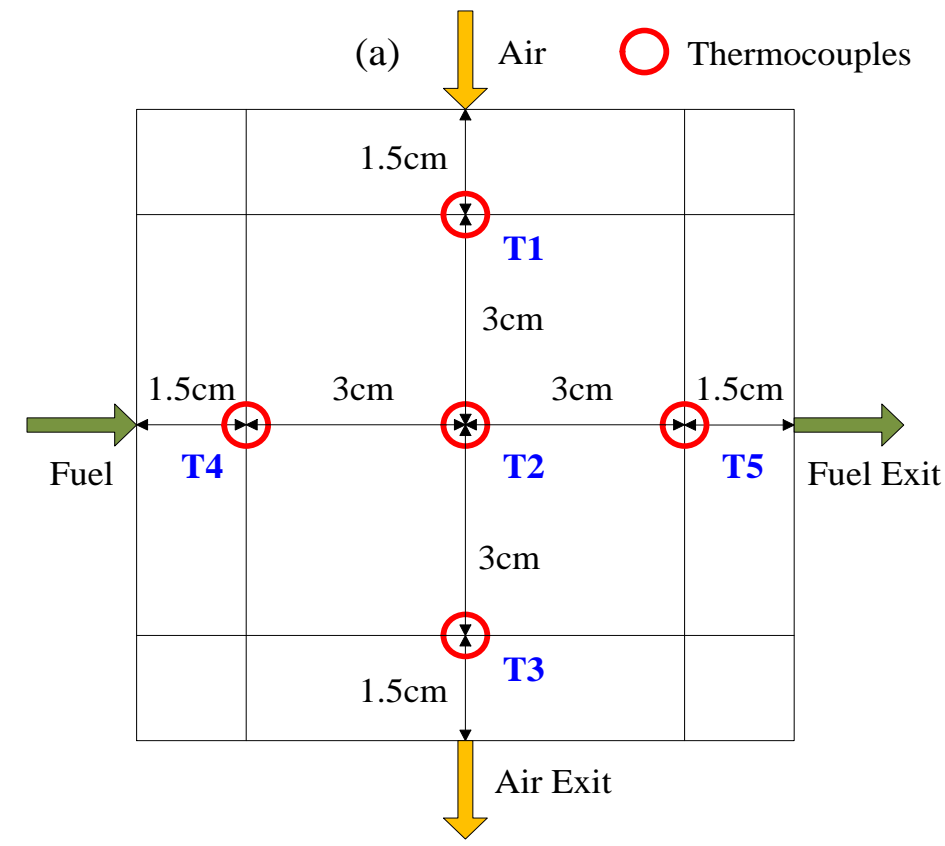

$(9 \mathrm{~cm} \times 9 \mathrm{~cm}$ active area $)$

(b)

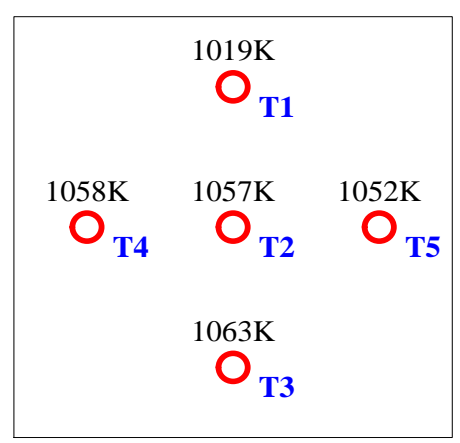

(Experiment) (c)

\begin{tabular}{|c|c|c|}
\hline \multirow[b]{2}{*}{${\stackrel{1055 K}{O_{T 4}}}^{-10}$} & $\stackrel{1028 \mathrm{~K}}{\mathrm{O}}_{\mathrm{T} 1}$ & \multirow[b]{2}{*}{$\begin{array}{c}1050 \mathrm{~K} \\
\mathrm{O}_{\mathrm{T}}\end{array}$} \\
\hline & ${\stackrel{1053 \mathrm{~K}}{\mathrm{O}_{\mathrm{T} 2}}}^{1}$ & \\
\hline & 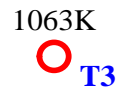 & \\
\hline
\end{tabular}

(Model) 
Fig. 5

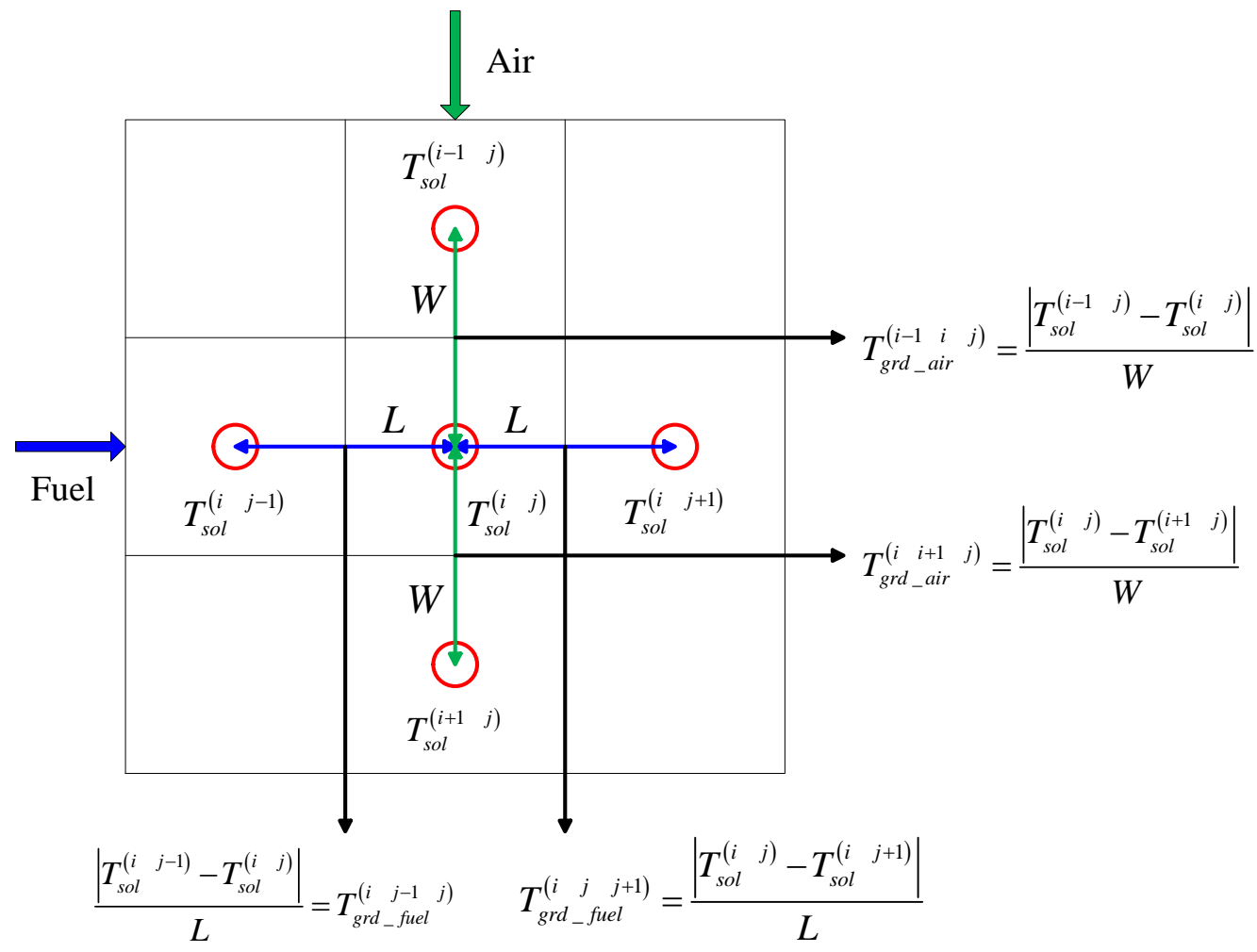


Fig. 6
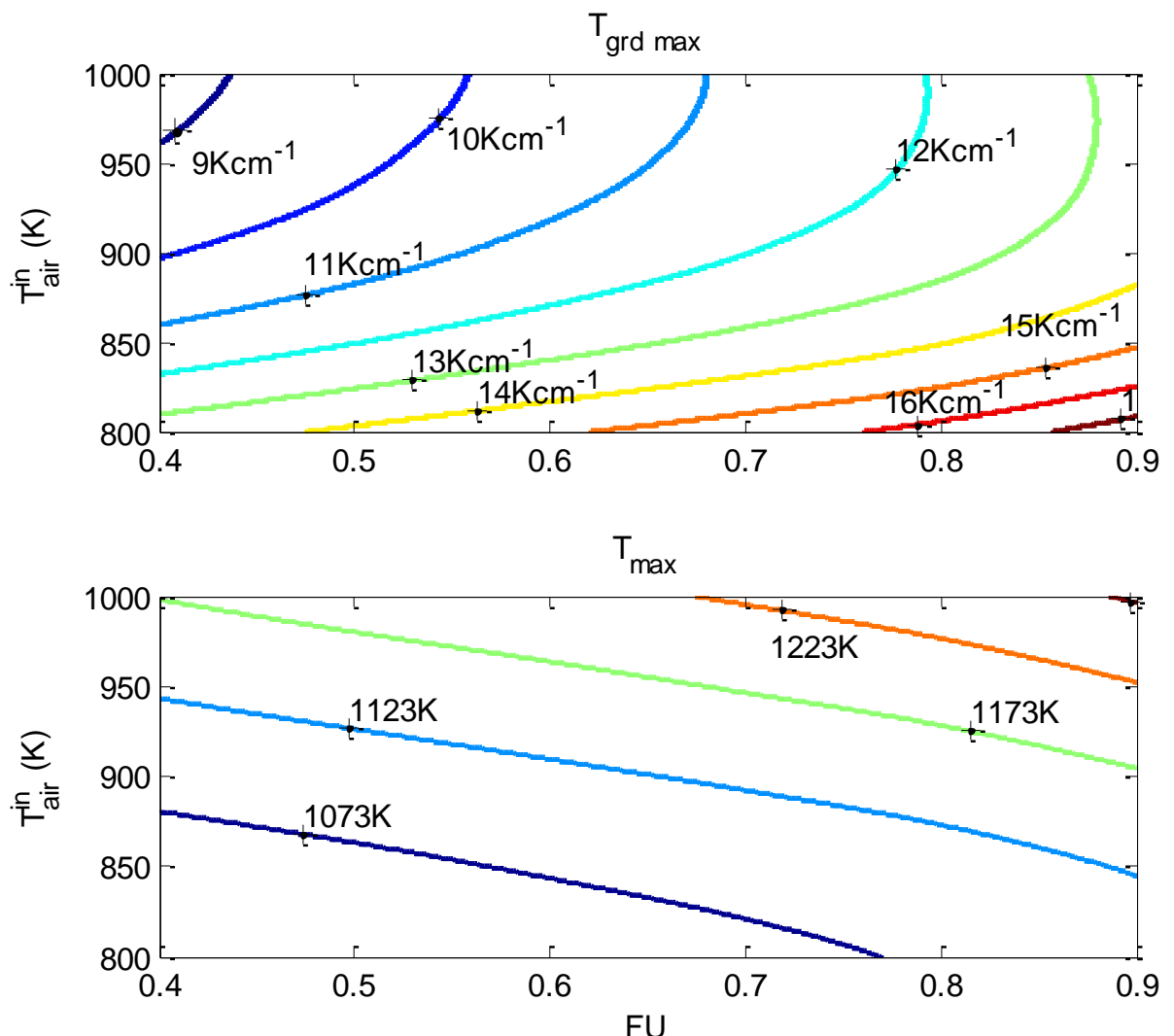
Fig. 7

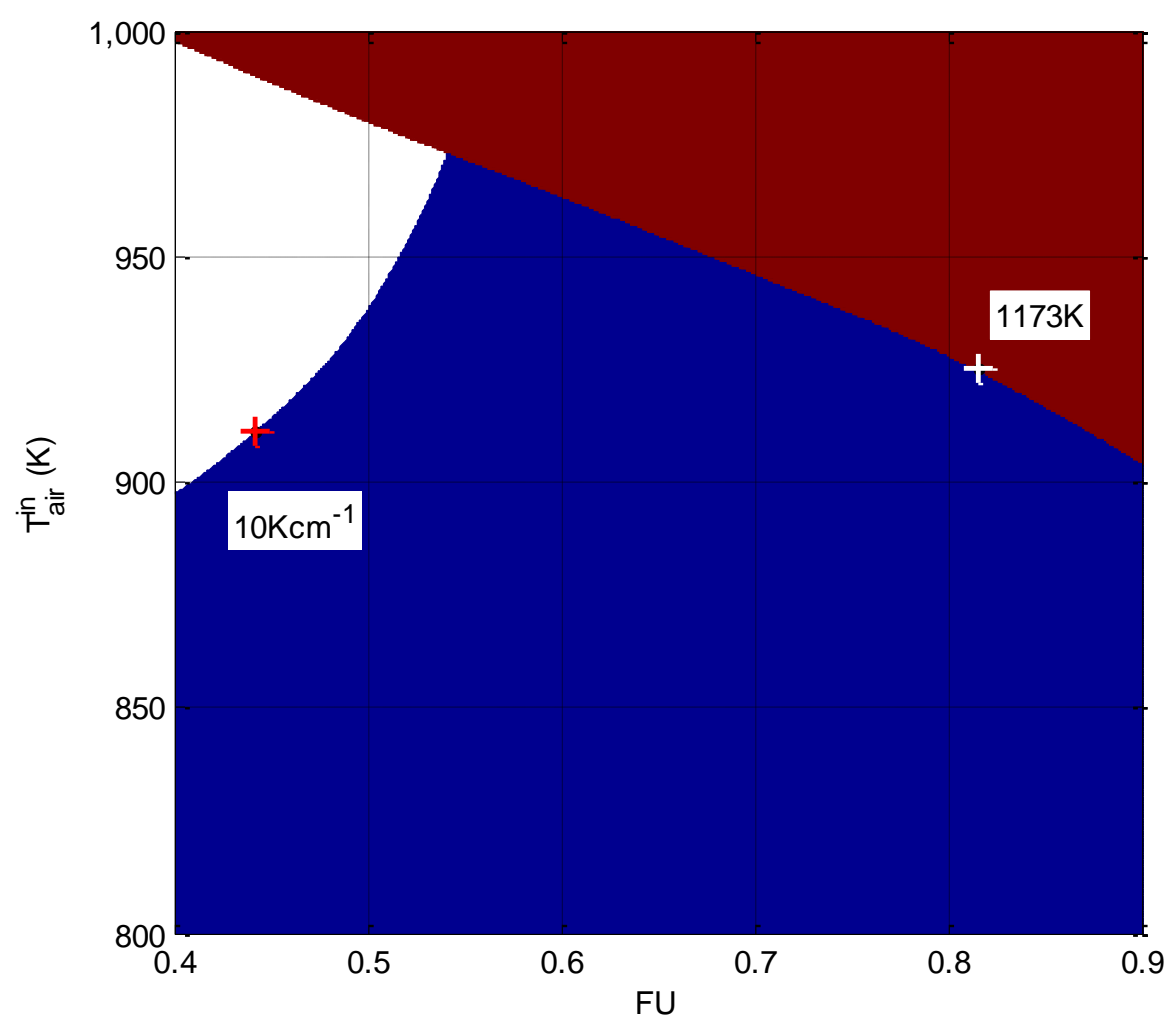


Fig. 8
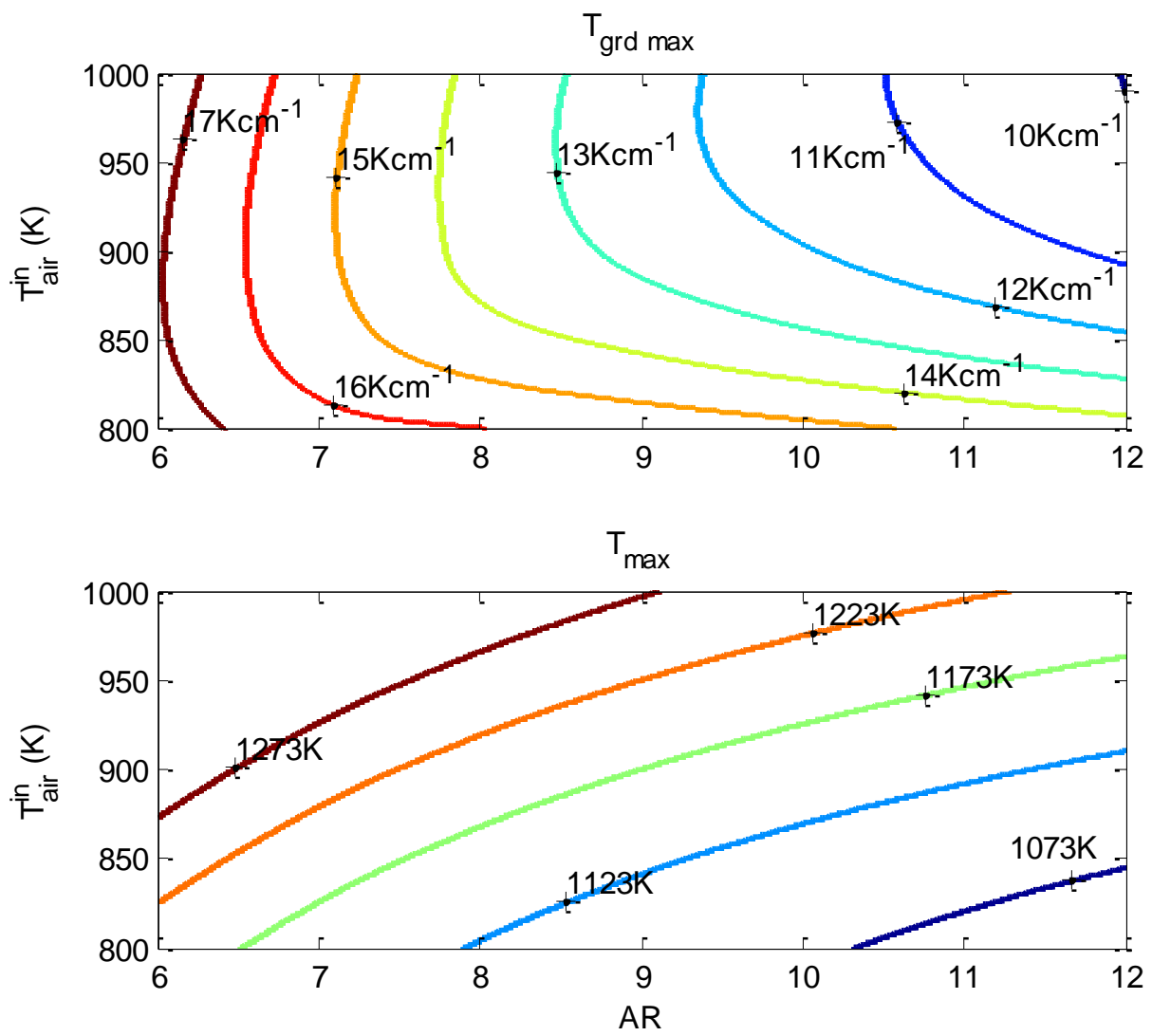
Fig. 9

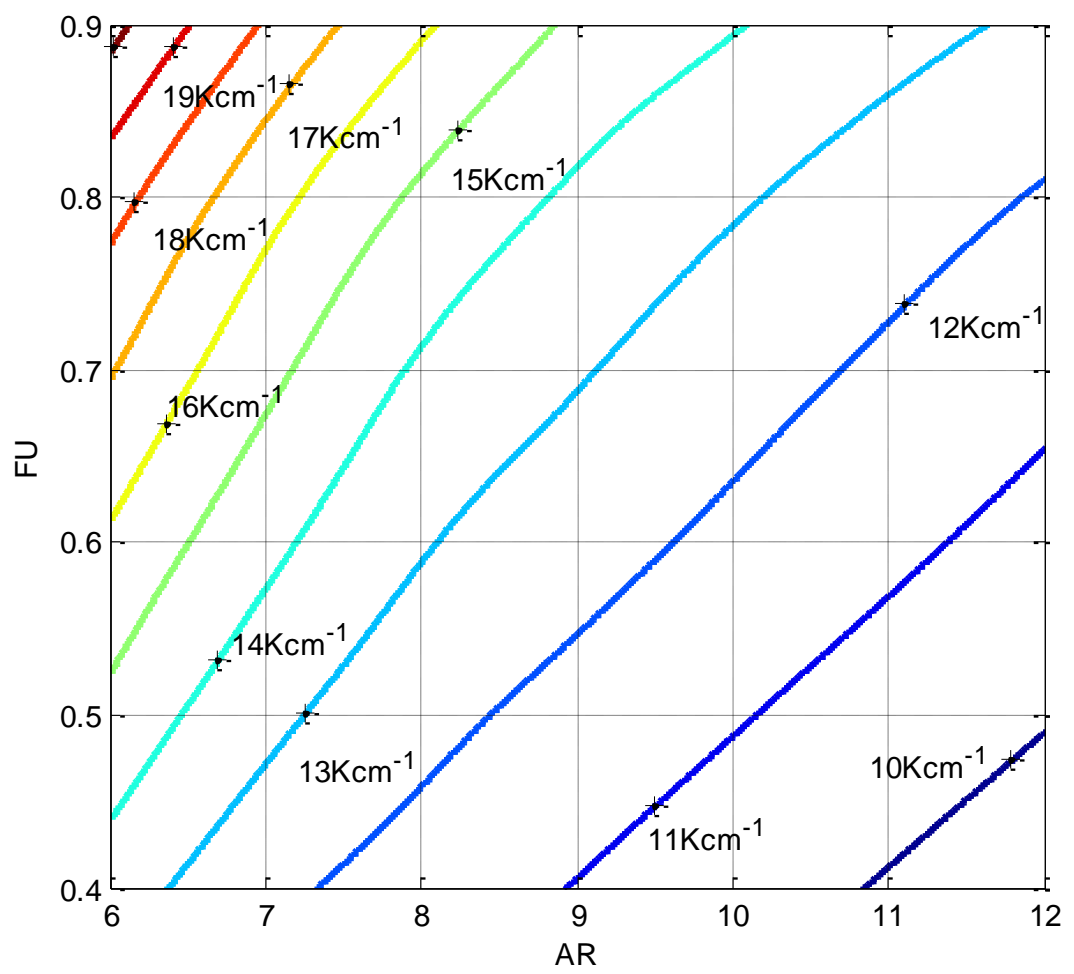


Fig. 10

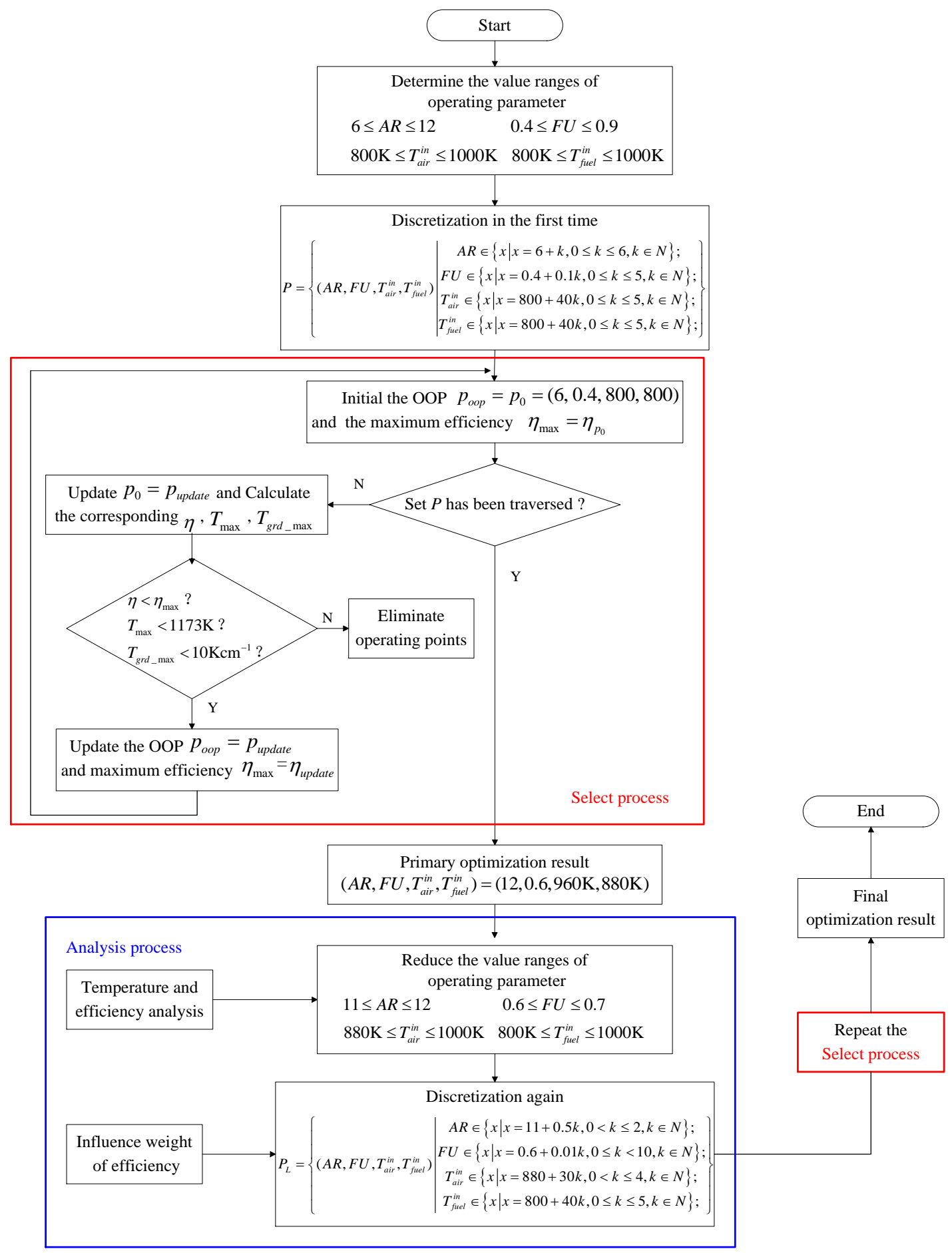


Fig. 11
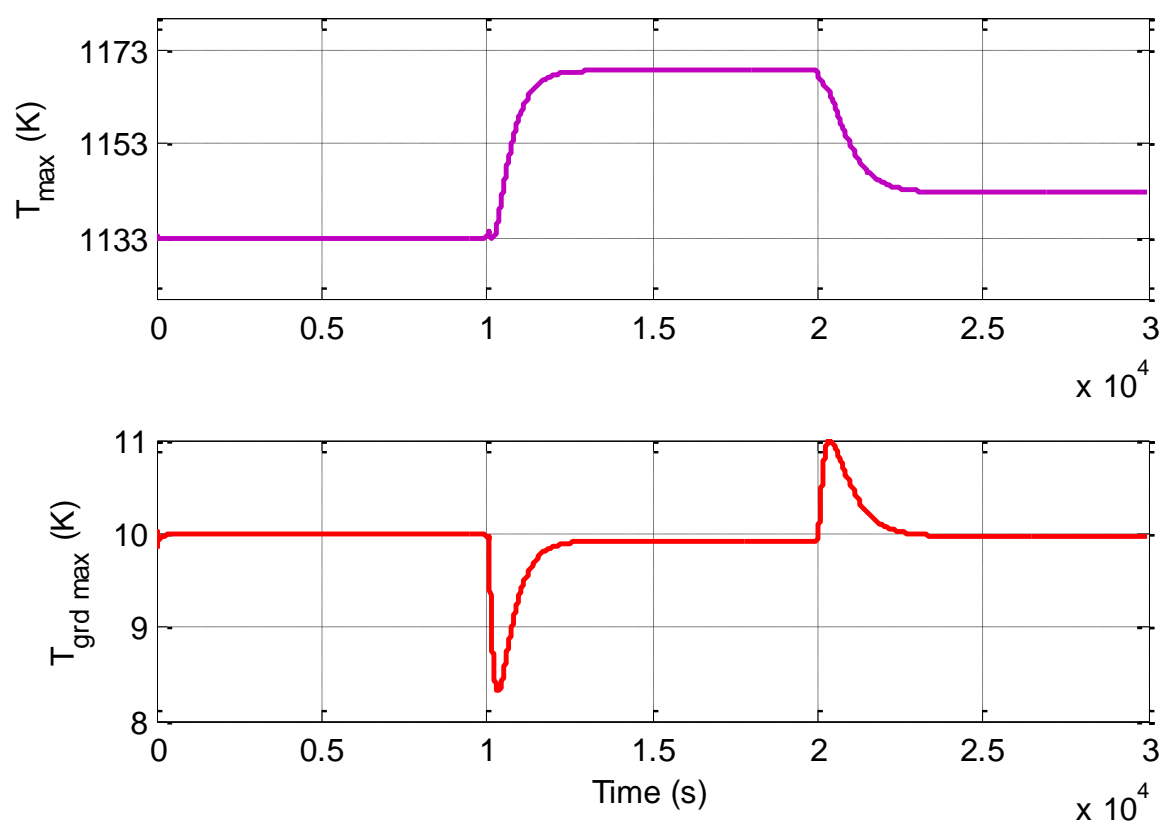
Fig. 12

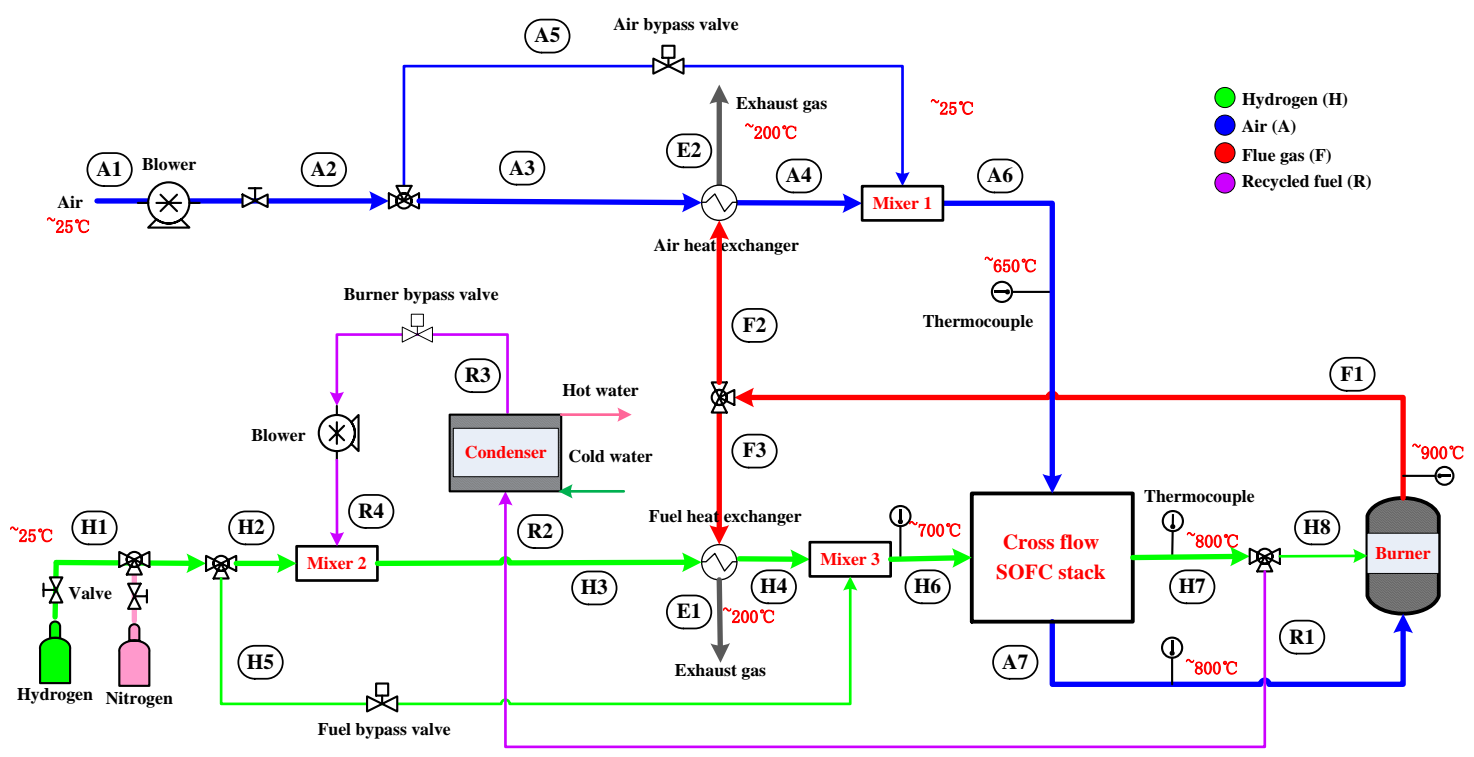


Fig. 13

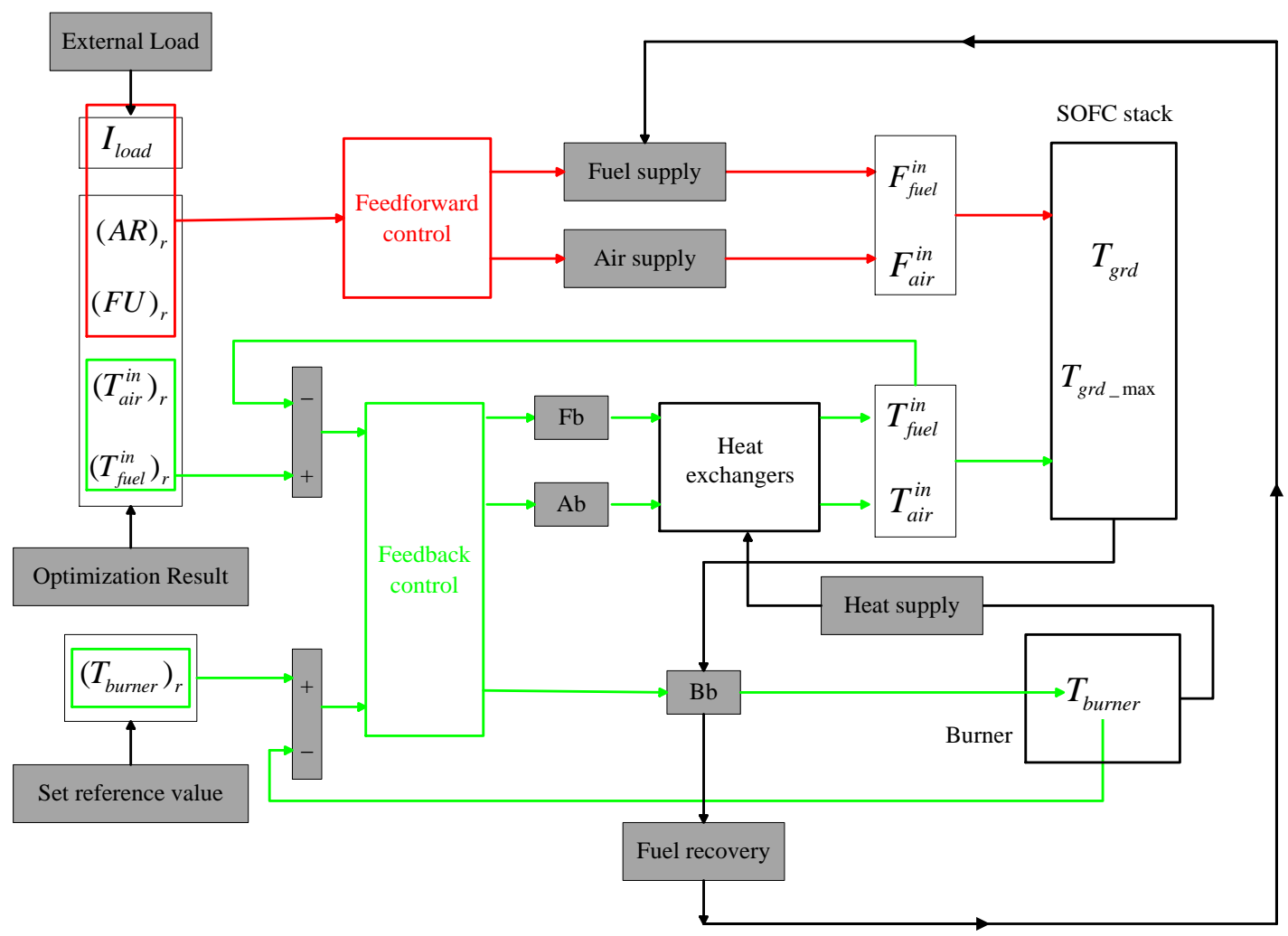


Fig. 14

(a)

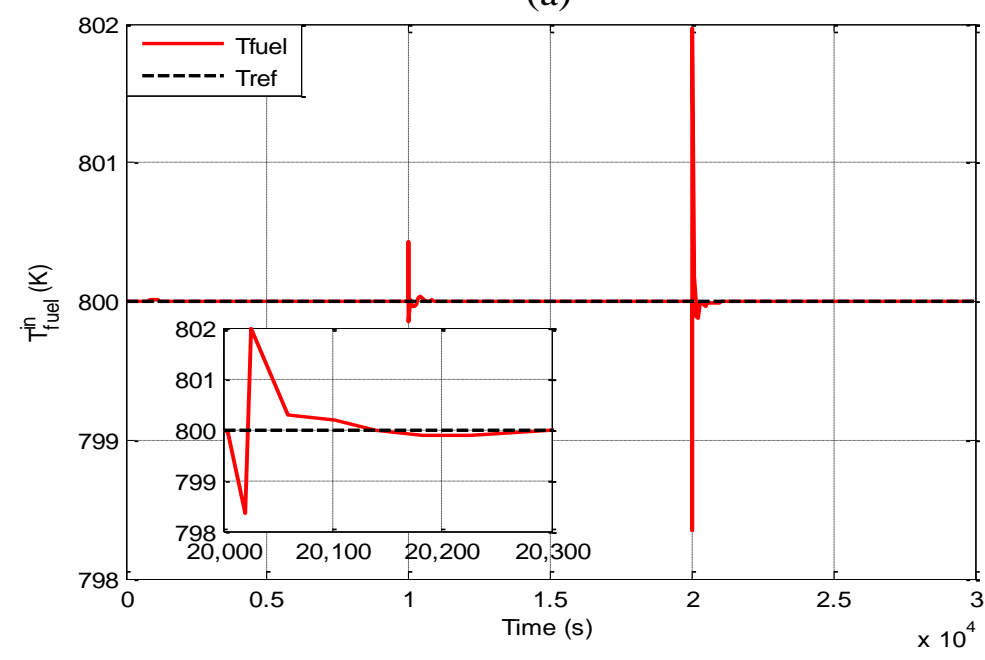

(b)

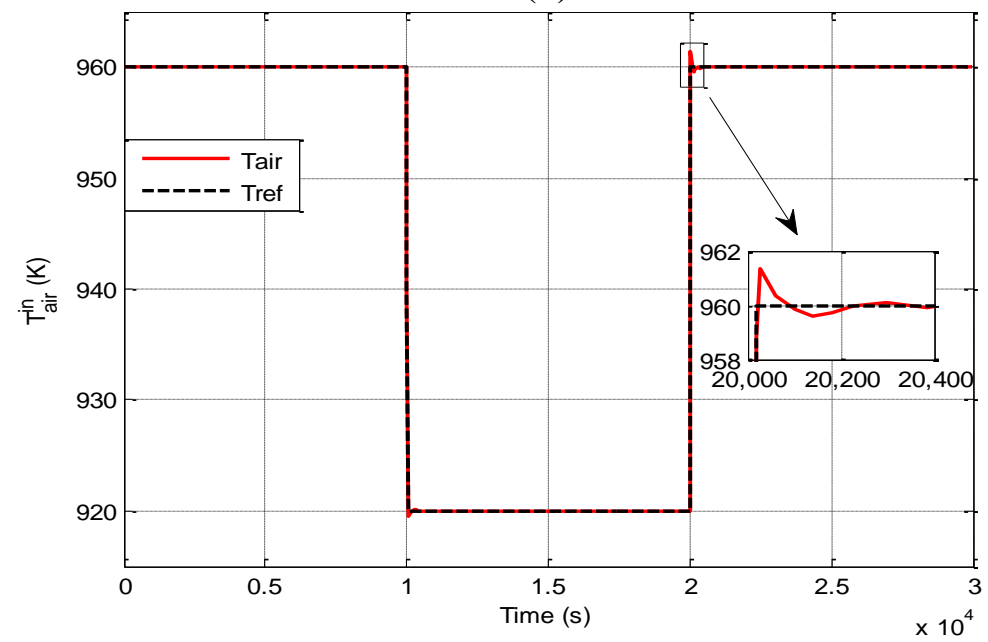

(c)

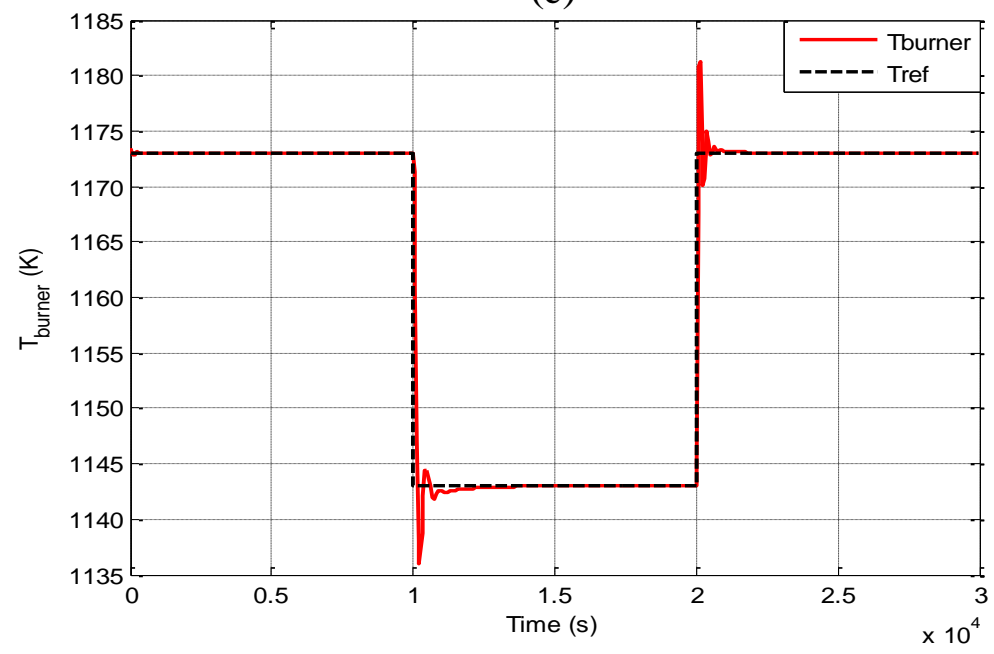


Fig. 15

(a)

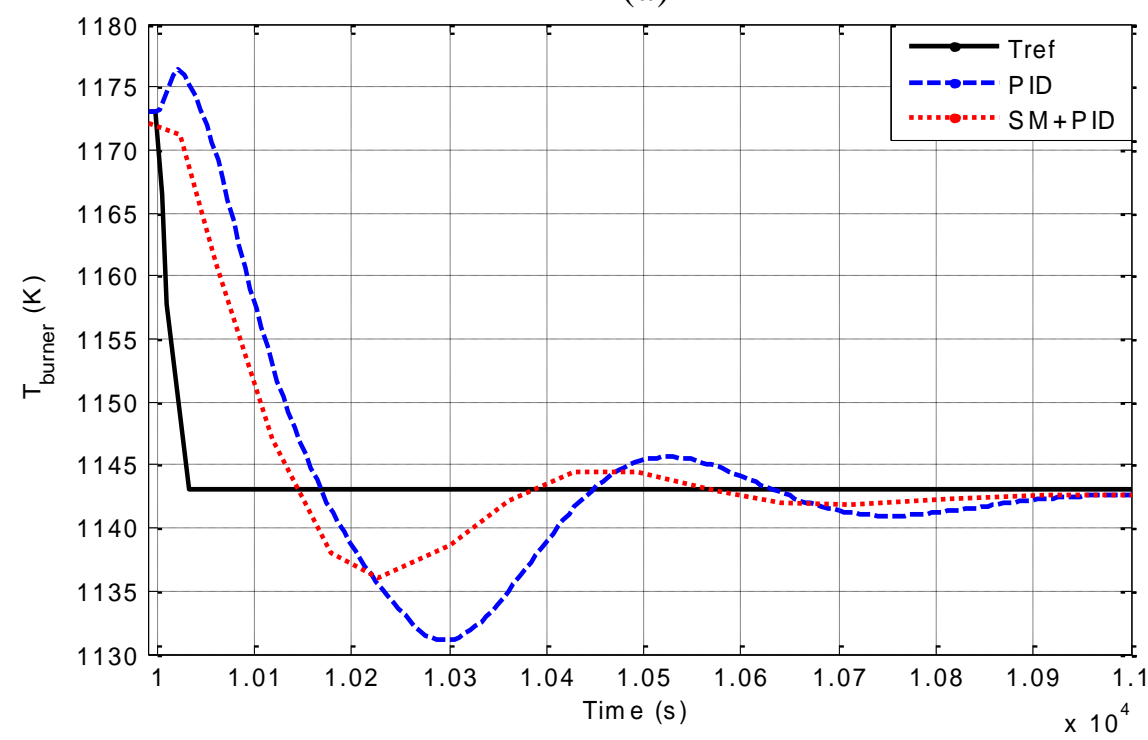

(b)

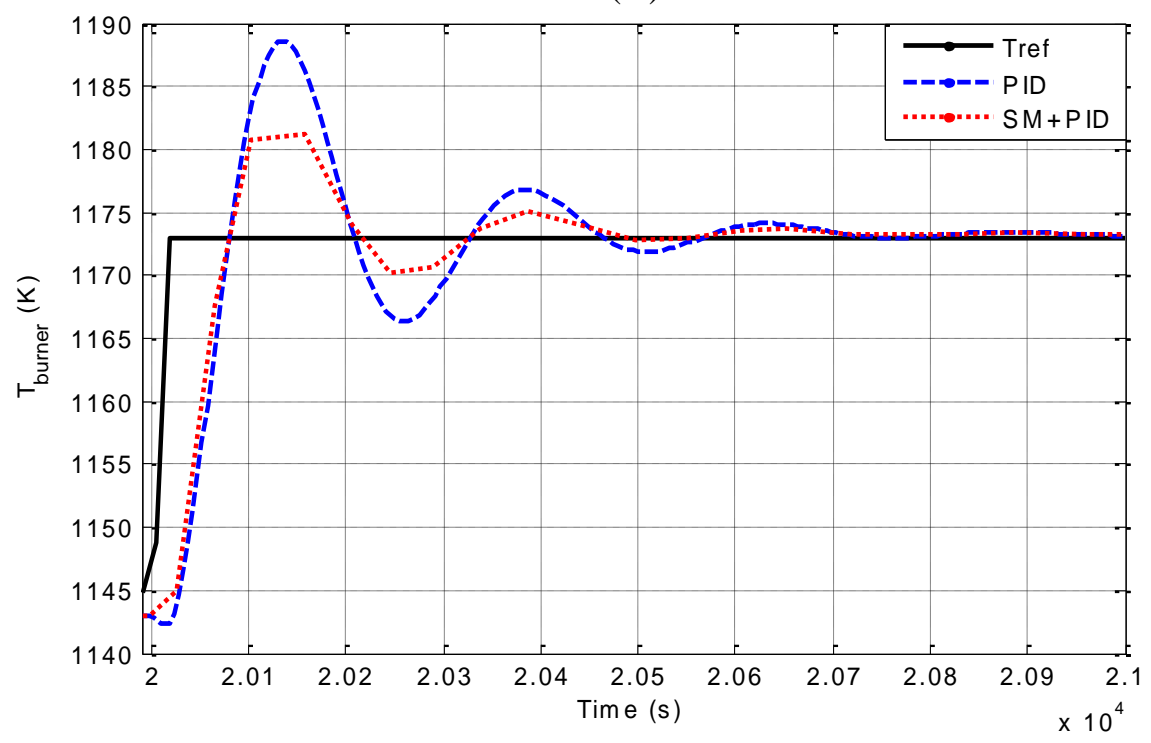

Tref: reference temperature value PID: PID control SM: sliding mode control 
Fig. 16

(a)

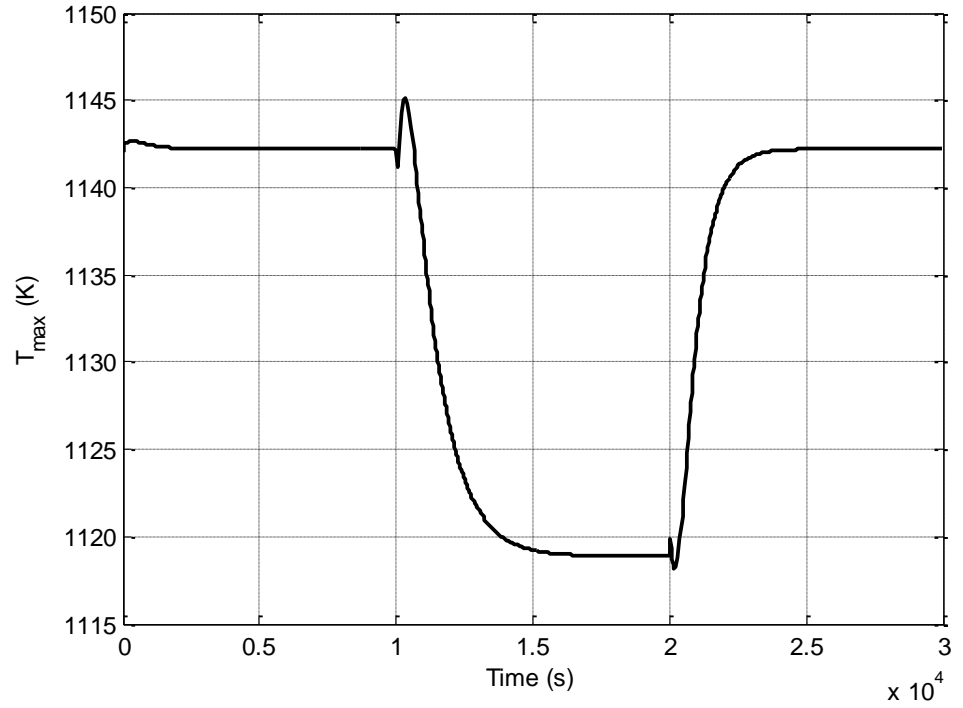

(b)

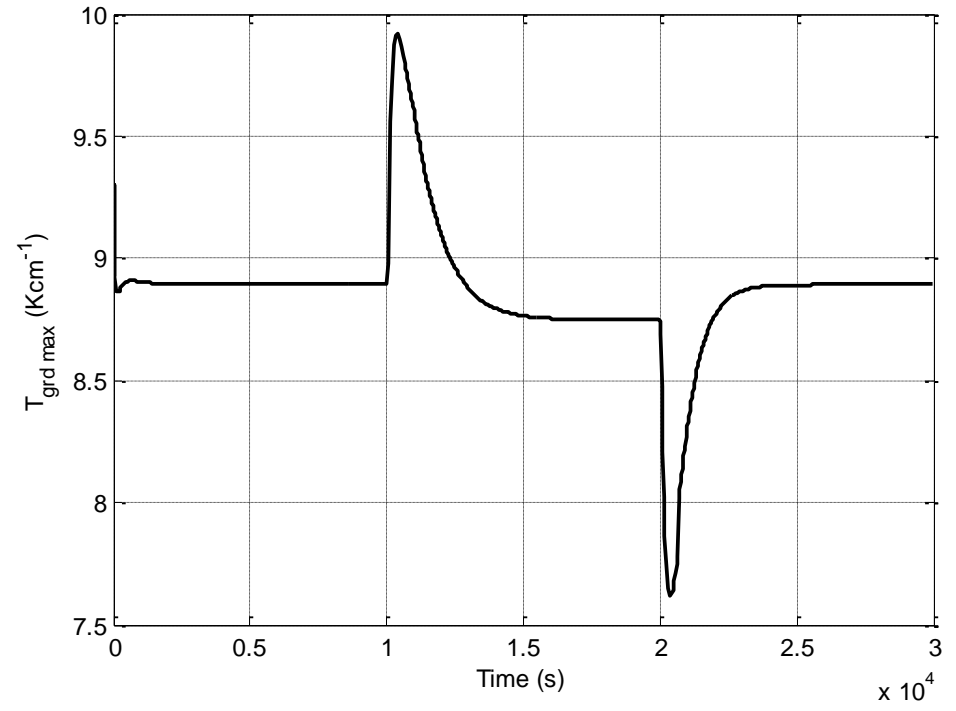


Fig. 17

(a)

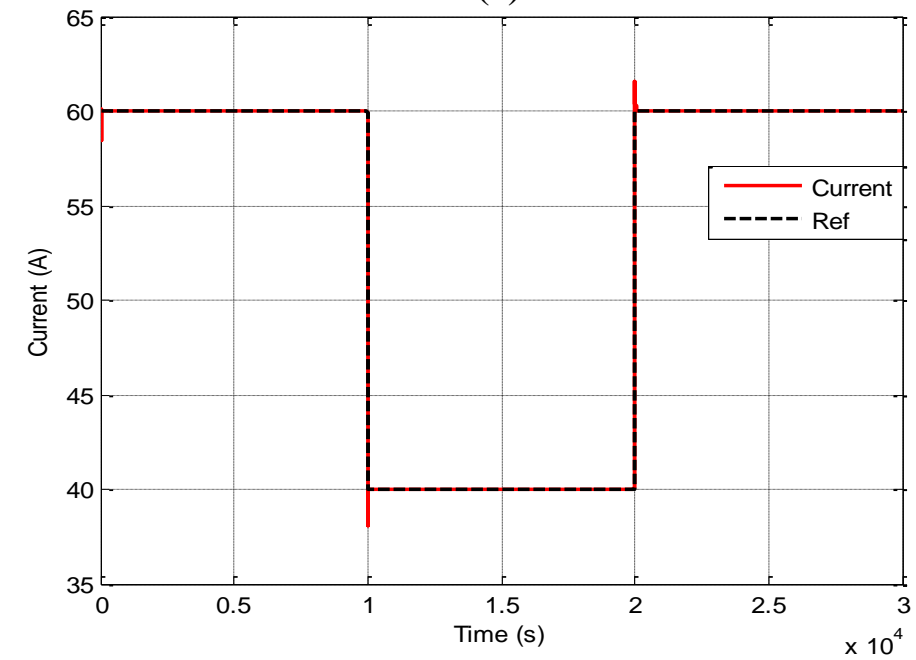

(b)

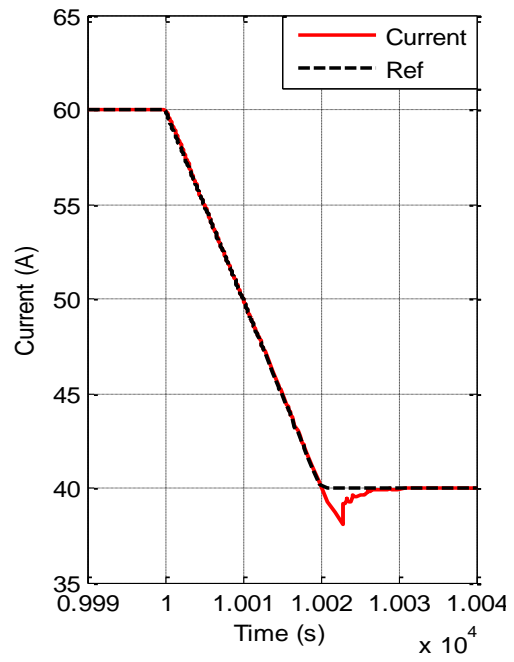

(c)

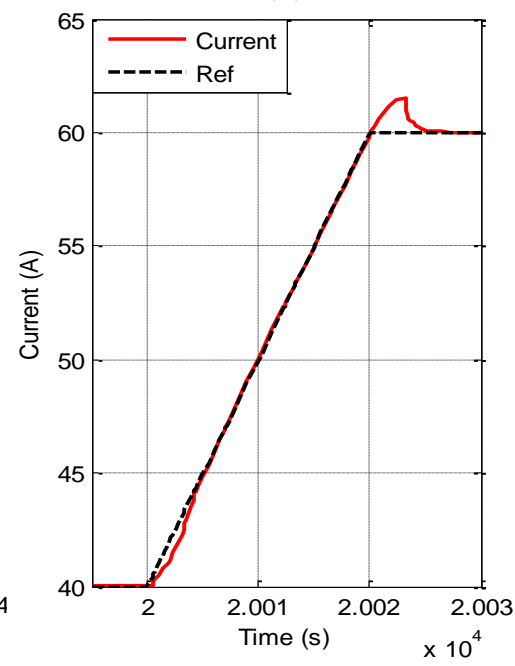


Fig. 18

(a)

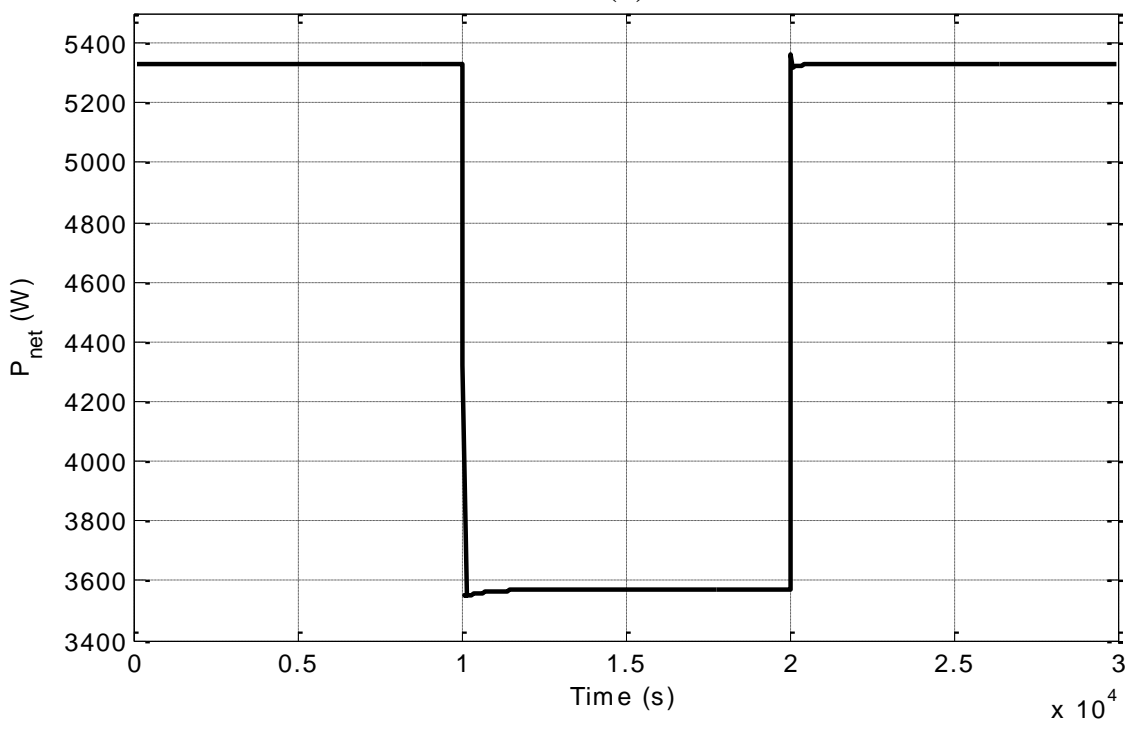

(b)

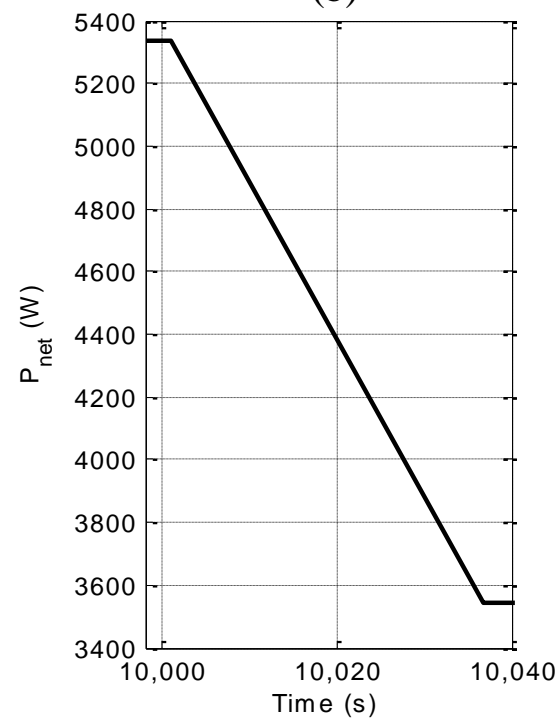

(c)

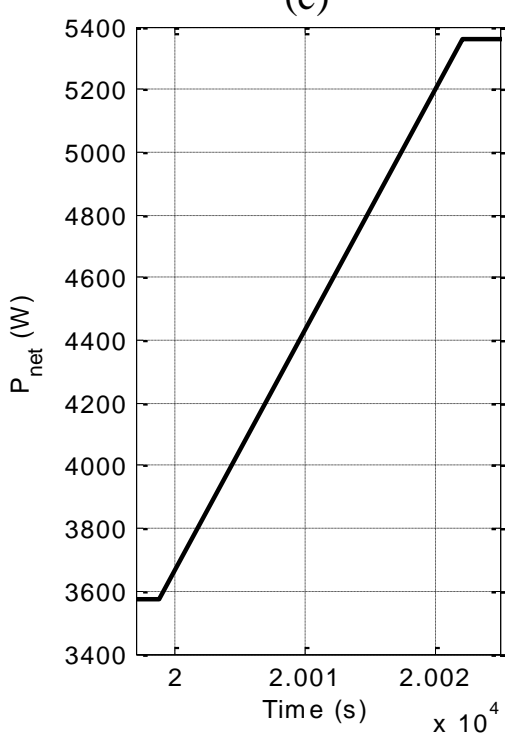


Fig. 19

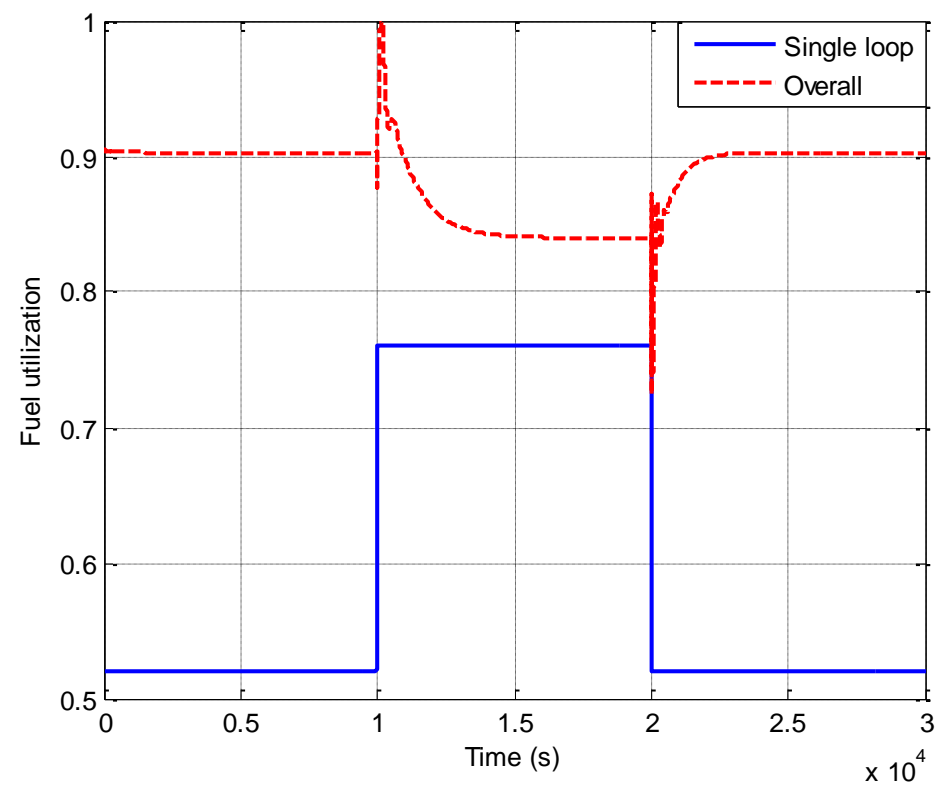


Fig. A.1

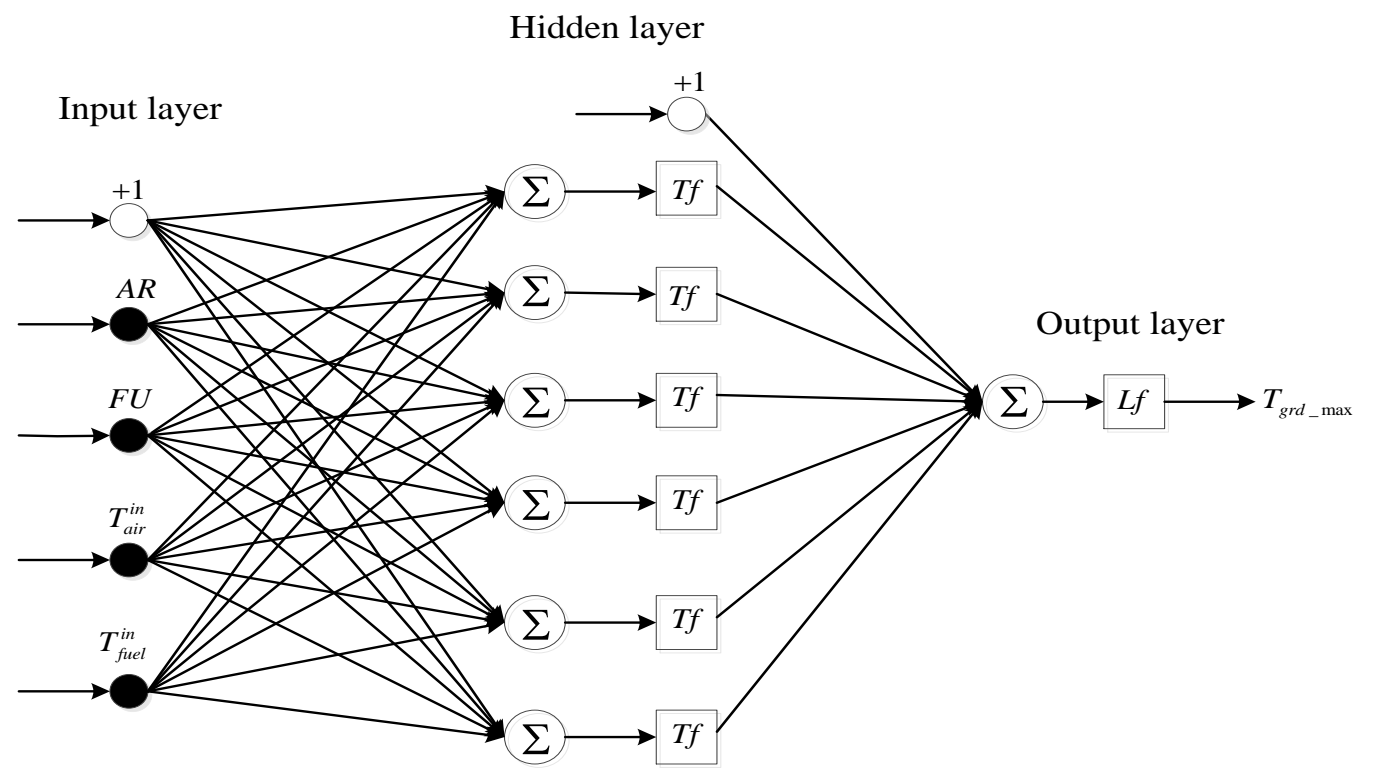


Table 1 Essential information of single cell

\begin{tabular}{|c|c|c|}
\hline Nomenclature & Variable & Value \\
\hline$L_{t h} h_{\text {cell }}$ & Length of cell & $0.1 \mathrm{~m}$ \\
\hline Wth $h_{\text {cell }}$ & Width of cell & $0.1 \mathrm{~m}$ \\
\hline$H_{a n}$ & Highness of anode channel & $0.001 \mathrm{~m}$ \\
\hline$H_{c a}$ & Highness of cathode channel & $0.002 \mathrm{~m}$ \\
\hline$P_{\text {active }}$ & Proportion of active area to cell area & 0.81 \\
\hline$k_{a n}$ & Heat transmission coefficient of anode & $0.05 \mathrm{~kW} \mathrm{~m}^{-2} \mathrm{~K}^{-1}$ \\
\hline$k_{c a}$ & Heat transmission coefficient of cathode & $0.1 \mathrm{kWm}^{-2} \mathrm{~K}^{-1}$ \\
\hline$k_{p e n}$ & Heat transmission coefficient of PEN & $0.002 \mathrm{kWm}^{-1} \mathrm{~K}^{-1}$ \\
\hline$k_{i c}$ & Heat transmission coefficient of interconnector & $0.0025 \mathrm{~kW} \mathrm{~m}^{-1} \mathrm{~K}^{-1}$ \\
\hline$\tau_{p e n}$ & Thickness of PEN & $0.0005 \mathrm{~m}$ \\
\hline$\tau_{i c}$ & Thickness of interconnector & $0.001 \mathrm{~m}$ \\
\hline$c_{p e n}$ & Specific heat capacity of PEN & $0.5 \mathrm{kJkg}^{-1} \mathrm{~K}^{-1}$ \\
\hline$c_{i c}$ & Specific heat capacity of interconnector & $0.62 \mathrm{~kJ} \mathrm{~kg}^{-1} \mathrm{~K}^{-1}$ \\
\hline
\end{tabular}


Table 2 Comparison of experimental and calculated voltage on different currents

\begin{tabular}{c|c|c|c|c|c}
\hline Current & 0A & 10A & 20A & 30A & 40A \\
\hline$V_{\exp }$ & $1.183 \mathrm{~V}$ & $0.956 \mathrm{~V}$ & $0.855 \mathrm{~V}$ & $0.765 \mathrm{~V}$ & $0.660 \mathrm{~V}$ \\
\hline$V_{\text {cell }}$ & $1.181 \mathrm{~V}$ & $0.948 \mathrm{~V}$ & $0.856 \mathrm{~V}$ & $0.775 \mathrm{~V}$ & $0.668 \mathrm{~V}$ \\
\hline
\end{tabular}

*Note: $V_{\exp }$ is the average voltage of single cell measured by experiment. $V_{\text {cell }}$ is the voltage of single cell calculated by the proposed model. 
Table 3 The OOPs obtained by preliminary efficiency optimization

\begin{tabular}{|c|c|c|c|c|c|c|c|c|}
\hline$I_{\text {tot }}$ & $A R$ & $F U$ & $T_{\text {air }}^{\text {in }}$ & $T_{\text {fuel }}^{\text {in }}$ & $T_{\text {grd_max }}$ & $T_{\max }$ & $\eta$ & $P_{\text {net }}$ \\
\hline $\mathbf{4 0 A}$ & 11 & 0.8 & $920 \mathrm{~K}$ & $800 \mathrm{~K}$ & $9.89 \mathrm{Kcm}^{-1}$ & $1142 \mathrm{~K}$ & $46.08 \%$ & $3605 \mathrm{~W}$ \\
\hline $\mathbf{6 0 A}$ & 12 & 0.6 & $960 \mathrm{~K}$ & $880 \mathrm{~K}$ & $9.80 \mathrm{Kcm}^{-1}$ & $1163 \mathrm{~K}$ & $33.71 \%$ & $5245 \mathrm{~W}$ \\
\hline $80 A$ & 11 & 0.4 & $960 \mathrm{~K}$ & $800 \mathrm{~K}$ & $9.94 \mathrm{Kcm}^{-1}$ & $1158 \mathrm{~K}$ & $22.58 \%$ & $7058 \mathrm{~W}$ \\
\hline
\end{tabular}

*Notes: $\eta$ is the power generating efficiency without considering fuel recovery. $P_{n e t}$ represents the net power of SOFC system after deducting the energy consumed by blower. 
Table 4 Errors of the identified ANN models

\begin{tabular}{|c|c|c|c|c|}
\hline Current & $\begin{array}{l}\text { Function to be } \\
\text { identified }\end{array}$ & $\begin{array}{c}\text { Number of } \\
\text { neurons }\end{array}$ & Maximum errors & Average errors \\
\hline \multirow{3}{*}{$40 \mathrm{~A}$} & $T_{\max }(\mathrm{K})$ & 6 & 3.7430 & 0.0023 \\
\hline & $T_{\text {grd_max }}\left(\mathrm{Kcm}^{-1}\right)$ & 6 & 0.3408 & 0.0002 \\
\hline & $\eta(\%)$ & 7 & 0.1693 & 0.0011 \\
\hline \multirow{3}{*}{ 60A } & $T_{\max }(\mathrm{K})$ & 7 & 3.2100 & 0.0105 \\
\hline & $T_{\text {grd_max }}\left(\mathrm{Kcm}^{-1}\right)$ & 6 & 0.2123 & 0.0010 \\
\hline & $\eta(\%)$ & 6 & 0.1728 & 0.0002 \\
\hline \multirow{3}{*}{$80 \mathrm{~A}$} & $T_{\max }(\mathrm{K})$ & 6 & 4.7663 & 0.0276 \\
\hline & $T_{g r d_{-} \max }\left(\mathrm{Kcm}^{-1}\right)$ & 7 & 0.3401 & 0.0021 \\
\hline & $\eta(\%)$ & 6 & 0.2071 & 0.0003 \\
\hline
\end{tabular}


Table 5 The influencing weights of operating parameters on $T_{\max }$

\begin{tabular}{|c|c|c|c|}
\hline & $\left.F_{\text {mean_abs }}\left(T_{\max }, x_{k}\right)\right|_{P}$ & $\left.F_{\max }\left(T_{\max }, x_{k}\right)\right|_{P}$ & $\left.F_{\min }\left(T_{\max }, x_{k}\right)\right|_{P}$ \\
\hline$x_{1}(A R)$ & 98.6349 & -26.0047 & -316.8484 \\
\hline$x_{2}(F U)$ & 58.3626 & 177.5374 & 21.5360 \\
\hline$x_{3}\left(T_{\text {air }}^{\text {in }}\right)$ & 88.9706 & 141.5992 & 24.9548 \\
\hline$x_{4}\left(T_{\text {fuel }}^{\text {in }}\right)$ & 12.9485 & 20.7553 & 6.2724 \\
\hline
\end{tabular}


Table 6 The influencing weights of operating parameters on $T_{\text {grd } \max }$

\begin{tabular}{|c|c|c|c|}
\hline & $\left.F_{\text {mean_abs }}\left(T_{\text {grd } \_ \text {max }}, x_{k}\right)\right|_{P}$ & $\left.F_{\max }\left(T_{g r d_{-} \max }, x_{k}\right)\right|_{P}$ & $\left.F_{\min }\left(T_{g r d_{-} \max }, x_{k}\right)\right|_{P}$ \\
\hline$x_{1}(A R)$ & 3.0966 & -0.5315 & -8.8542 \\
\hline$x_{2}(F U)$ & 2.4430 & 6.7085 & 1.0873 \\
\hline$x_{3}\left(T_{\text {air }}^{\text {in }}\right)$ & 1.6562 & 1.5982 & -6.0573 \\
\hline$x_{4}\left(T_{\text {fuel }}^{\text {in }}\right)$ & 0.4819 & 0.8159 & 0.1403 \\
\hline
\end{tabular}


Table 7 The influencing weights of operating parameters on $\eta$

\begin{tabular}{|c|c|c|c|}
\hline & $\left.F_{\text {mean_abs }}\left(\eta, x_{k}\right)\right|_{P_{s}}$ & $\left.F_{\max }\left(\eta, x_{k}\right)\right|_{P_{s}}$ & $\left.F_{\min }\left(\eta, x_{k}\right)\right|_{P_{s}}$ \\
\hline$x_{1}(A R)$ & 1.0309 & -0.7777 & -1.4389 \\
\hline$x_{2}(F U)$ & 11.3169 & 11.5484 & 10.6799 \\
\hline$x_{3}\left(T_{\text {air }}^{\text {in }}\right)$ & 0.2392 & 0.9708 & -0.2238 \\
\hline$x_{4}\left(T_{\text {fuel }}^{\text {in }}\right)$ & 0.0141 & 0.0205 & -0.0100 \\
\hline
\end{tabular}

*Note: $P_{s}=\left\{p_{0} \mid p_{0} \in P\right.$ and the stack temperature safety can be guaranteed on $\left.p_{0}\right\} \cdot P$ is the operating parameter set defined by Eq. (12). 
Table 8 The OOPs obtained by secondary efficiency optimization

\begin{tabular}{|c|c|c|c|c|c|c|c|c|}
\hline$I_{\text {tot }}$ & $A R$ & $F U$ & $T_{\text {air }}^{\text {in }}$ & $T_{\text {fuel }}^{\text {in }}$ & $T_{\text {grd_max }}$ & $T_{\max }$ & $\eta$ & $P_{\text {net }}$ \\
\hline $\mathbf{4 0 A}$ & 11.5 & 0.85 & $910 \mathrm{~K}$ & $800 \mathrm{~K}$ & $9.99 \mathrm{Kcm}^{-1}$ & $1133 \mathrm{~K}$ & $47.99 \%$ & $3523 \mathrm{~W}$ \\
\hline $\mathbf{6 0 A}$ & 12 & 0.65 & $940 \mathrm{~K}$ & $800 \mathrm{~K}$ & $9.97 \mathrm{Kcm}^{-1}$ & $1143 \mathrm{~K}$ & $36.11 \%$ & $5187 \mathrm{~W}$ \\
\hline $\mathbf{8 0 A}$ & 12 & 0.5 & $970 \mathrm{~K}$ & $800 \mathrm{~K}$ & $9.92 \mathrm{Kcm}^{-1}$ & $1169 \mathrm{~K}$ & $27.19 \%$ & $6760 \mathrm{~W}$ \\
\hline
\end{tabular}


Table 9 The OOPs with temperature safety redundancy

\begin{tabular}{|c|c|c|c|c|c|c|c|c|}
\hline$I_{\text {tot }}$ & $A R$ & $F U$ & $T_{\text {air }}^{\text {in }}$ & $T_{\text {fuel }}^{\text {in }}$ & $T_{\text {grd_max }}$ & $T_{\max }$ & $\eta$ & $P_{n e t}$ \\
\hline $\mathbf{4 0 A}$ & 12 & 0.76 & $920 \mathrm{~K}$ & $800 \mathrm{~K}$ & $8.97 \mathrm{Kcm}^{-1}$ & $1119 \mathrm{~K}$ & $43.64 \%$ & $3579 \mathrm{~W}$ \\
\hline $\mathbf{6 0 A}$ & 12 & 0.52 & $960 \mathrm{~K}$ & $800 \mathrm{~K}$ & $8.89 \mathrm{Kcm}^{-1}$ & $1142 \mathrm{~K}$ & $29.71 \%$ & $5327 \mathrm{~W}$ \\
\hline
\end{tabular}


Table 10 The parameters of PID in the controller

\begin{tabular}{|c|c|c|c|c|}
\hline $\begin{array}{c}\text { Controlling } \\
\text { variables }\end{array}$ & $\begin{array}{c}\text { Controlled } \\
\text { variables }\end{array}$ & $k_{P}$ & $k_{I}$ & $k_{D}$ \\
\hline$F b$ & $T_{\text {fuel,st }}^{\text {in }}$ & 0.001 & 0.0003 & 0 \\
\hline$A b$ & $T_{\text {air }, s t}^{\text {in }}$ & 0.001 & 0.0003 & 0 \\
\hline$B b$ & $T_{\text {burner }}$ & 0.001 & 0.0003 & 0.001 \\
\hline
\end{tabular}


Table A.1 Errors of ANN models with different structures

\begin{tabular}{|c|c|c|}
\hline $\begin{array}{c}\text { Number of neurons in } \\
\text { the hidden layer }\end{array}$ & Maximum error & Average error \\
\hline $\mathbf{4}$ & 0.2391 & 0.0015 \\
\hline $\mathbf{5}$ & 0.2404 & 0.0020 \\
\hline $\mathbf{6}$ & 0.2123 & 0.00097 \\
\hline $\mathbf{7}$ & 0.2277 & 0.0013 \\
\hline
\end{tabular}

